\title{
The effects of antenatal dietary and lifestyle advice for women who are overweight or obese on maternal diet and physical activity: the LIMIT randomised trial
}

Jodie M Dodd ${ }^{1,2^{*}}$, Courtney Cramp ${ }^{1}$, Zhixian Sui ${ }^{1}$, Lisa N Yelland ${ }^{1,3,4}$, Andrea R Deussen ${ }^{1}$, Rosalie M Grivell ${ }^{1,2}$, Lisa J Moran ${ }^{1}$, Caroline A Crowther ${ }^{1,8}$, Deborah Turnbull ${ }^{5}$, Andrew J McPhee ${ }^{6}$, Gary Wittert ${ }^{7}$, Julie A Owens ${ }^{1}$, Jeffrey S Robinson ${ }^{1}$ and For the LIMIT Randomised Trial Group

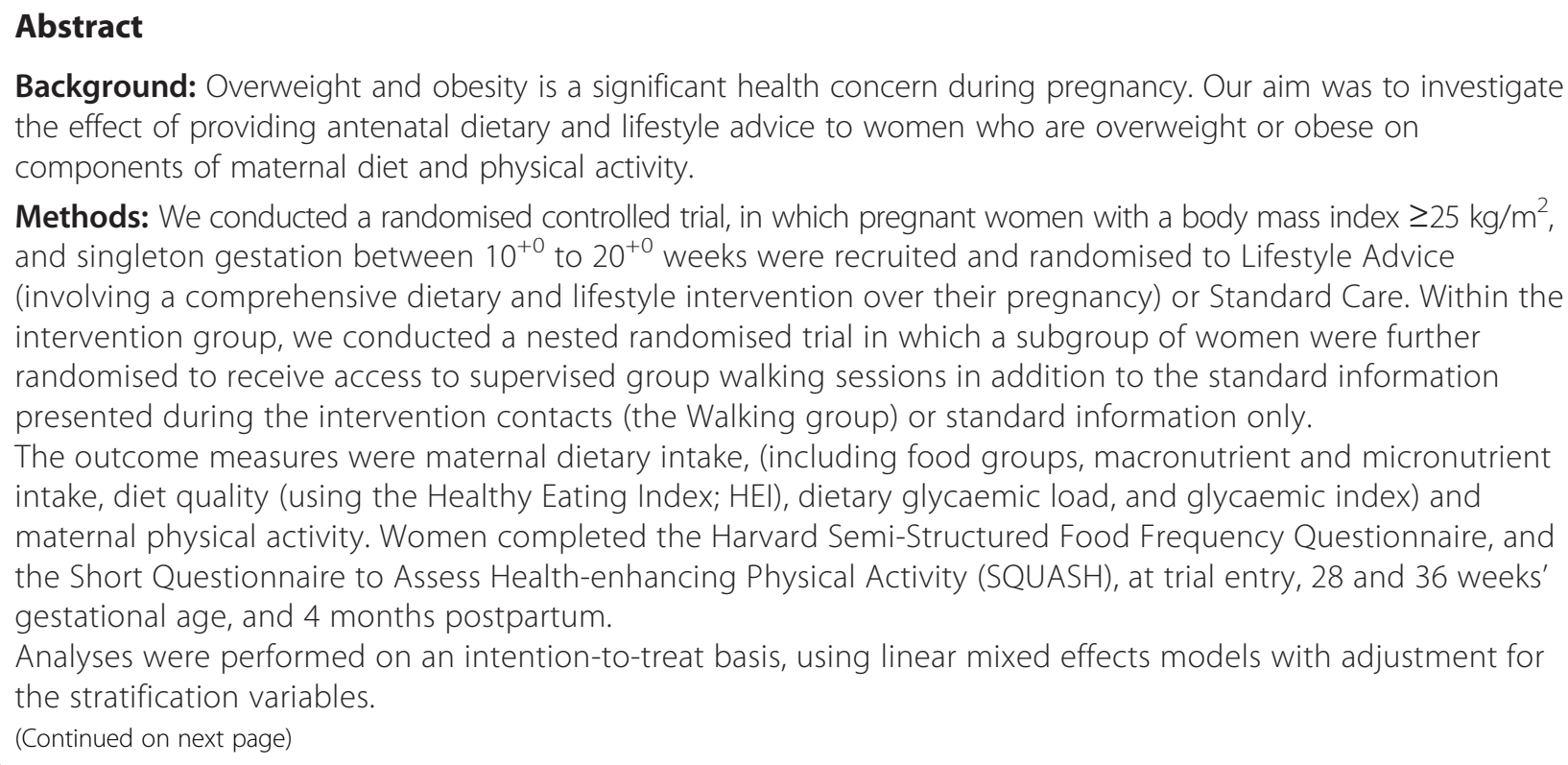

\footnotetext{
* Correspondence: jodie.dodd@adelaide.edu.au

'School of Paediatrics and Reproductive Health, and The Robinson Research

Institute, The University of Adelaide, Adelaide, Australia

2Department of Perinatal Medicine, Women's and Babies Division, The

Women's and Children's Hospital, North Adelaide, Australia

Full list of author information is available at the end of the article
} 
(Continued from previous page)

Results: Women randomised to Lifestyle Advice demonstrated a statistically significant increase in the number of servings of fruit and vegetables consumed per day, as well as increased consumption of fibre, and reduced percentage energy intake from saturated fats $(P<0.05$ for all). Maternal HEI was significantly improved at both 28 (73.35 \pm 6.62 versus $71.86 \pm 7.01$; adjusted difference in means $1.58 ; 95 \% \mathrm{Cl} 0.89$ to $2.27 ; P<0.0001)$ and 36 (72.95 \pm 6.82 versus $71.17 \pm 7.69$; adjusted difference in means $1.77 ; 95 \% \mathrm{Cl} 1.01$ to $2.53 ; P<0.0001)$ weeks. There were no differences in dietary glycaemic index or glycaemic load. Women randomised to Lifestyle Advice also demonstrated greater total physical activity (adjusted difference in means 359.76 metabolic equivalent task units (MET) minutes/week; $95 \% \mathrm{Cl} 74.87$ to $644.65 ; P=0.01$ ) compared with women receiving Standard Care. The supervised walking group was poorly utilised.

Conclusions: For women who are overweight or obese, antenatal lifestyle advice improves maternal diet and physical activity during pregnancy.

Please see related articles: http://www.biomedcentral.com/1741-7015/12/163 and http://www.biomedcentral. com/1741-7015/12/201.

Trial registration: Australian and New Zealand Clinical Trials Registry (ACTRN12607000161426)

Keywords: Pregnancy, Overweight and obesity, Diet composition, Physical activity, Randomised trial, Dietary and lifestyle intervention

\section{Background}

Obesity is recognised as a significant global health problem [1], with well-documented risks for pregnant women and their infants, which rise with increasing maternal body mass index (BMI) [2,3]. Current clinical care guidelines indicate that ideally, women should be counselled prior to conception about the increased pregnancy risks associated with obesity, and encouraged to make lifestyle changes to reduce the risk of subsequent complications during pregnancy and childbirth through weight loss [4,5]. However, with data from Australia, the USA and UK suggesting more than $50 \%$ of women enter pregnancy with a BMI in excess of $25 \mathrm{~kg} / \mathrm{m}^{2}$ [4,6,7], considerable attention has been directed towards evaluating interventions to limit gestational weight gain, and their effect on maternal and infant health outcomes [8-10]. Research has focused on the effects of dietary and lifestyle interventions to limit gestational weight gain, particularly among women who are overweight or obese [8-10], and there is limited information to date relating specifically to the effective components of these antenatal interventions, with suggestions that interventions designed to limit gestational weight gain through modification of diet may be more effective than those designed to increase physical activity alone [10].

Dietary quality can be assessed by utilising a number of different tools, including principal component analysis and use of dietary quality indices comparing nutritional intake with recommendations for healthy eating or dietary guidelines. A decrease in dietary quality, when utilising these measures as a comprehensive indicator of dietary intake, is associated with increased weight gain over time [11], as well as increased all-cause mortality and morbidity risk, specifically in relation to cardiovascular disease and some malignancies [12]. Compared with women of normal BMI, women who are overweight or obese demonstrate poorer diet quality during pregnancy [13], which continues into the early postpartum period [14]. When specifically compared with women of healthy weight, pregnant women who are overweight or obese demonstrate reduced intake of grains, vegetables, iron and folate $[13,15,16]$. With regard to clinical outcomes, poor diet quality during pregnancy has been associated with an increased risk of adverse pregnancy outcomes, including glucose intolerance and pre-eclampsia [17].

Dietary glycaemic index (GI) was developed as a tool for individuals with diabetes [18], ranking the post-prandial glycaemic response to ingested carbohydrates against a reference of either pure glucose or white bread, and the glycaemic load (GL) is the product of the glycaemic index and the amount of dietary carbohydrate [19]. Consumption of foods with low glycaemic index have been shown to be associated with reduced carbohydrate-induced post-prandial glycaemia [20]. Furthermore, a low glycaemic index or glycaemic load diet has been associated with improved weight loss through potential effects on hunger and energy intake [21]. Of relevance to pregnant women is the effect of maternal glycaemia on the placental transfer of glucose to the fetus, acting as a substrate for growth and development. While some studies have identified associations between maternal consumption of a low glycaemic index or glycaemic load diet and lower gestational weight gain [22,23] or lower infant birth weight [24], these findings are not universal, with other studies demonstrating no effect on infant birth weight [23,25-27]. 
Exercise during pregnancy is considered beneficial, improving maternal wellbeing and cardiovascular performance $[28,29]$. More specifically, exercise in pregnancy has been associated with a reduction in the risk of gestational diabetes [30,31], pre-eclampsia [32], and operative birth [33], and with improvements in fetal growth [34,35]. The American College of Obstetricians and Gynecologists (ACOG) has advocated that all pregnant women, without contraindications to exercising, should be active and participate in mild-to-moderate exercise for at least 30 minutes on most days of the week [36]. However, the recommendations for women who have been previously inactive or who have pregnancy complications are less clear-cut, requiring individual consideration [36]. ACOG recommend that pregnant women who are overweight or obese should be encouraged to follow an exercise programme in order to optimise health outcomes for both the woman and her infant [37]. Despite the proposed benefits of exercise, physical activity has been reported to decline over the course of pregnancy among women of all BMI categories, but is particularly evident among women who are overweight or obese [38-40], with a large proportion of women not attaining the recommended amount of exercise.

The primary findings of the LIMIT randomised trial evaluating the provision of antenatal dietary and lifestyle advice to women who were overweight or obese, have been reported previously, and indicate a significant $18 \%$ relative risk reduction in the chance of an infant being born with birth weight above $4 \mathrm{~kg}$ [41]. We now report the effect of providing antenatal dietary and lifestyle advice on specific components of maternal diet, including food groups, macronutrient and micronutrient consumption, dietary quality, and dietary glycaemic load and index, and maternal physical activity.

\section{Methods \\ Ethics}

Ethics approval was granted by the Women's and Children's Local Health Network Human Research and Ethics Committee at the Women's and Children's Hospital, the Central Northern Adelaide Health Service Ethics of Human Research Committee (Lyell McEwin Hospital) and the Flinders Clinical Research Ethics Committee (Flinders Medical Centre). All participants provided written informed consent.

\section{Study design}

The study was a multicentre randomised trial across the three major metropolitan maternity hospitals within Adelaide, South Australia. The methods [42] and primary findings [41] of the LIMIT randomised trial have been reported previously, and the trial has been registered on the Australian and New Zealand Clinical Trials Registry
(ACTRN12607000161426). Additional dietary and physical activity outcomes were added to the final working protocol, reflecting piloting and feasibility assessment, and finalization of specific questionnaires. These amendments were pre-specified in the final working protocol, early in the conduct of the trial, and prior to any analyses being undertaken.

\section{Inclusion and exclusion criteria}

Women with a BMI $\geq 25 \mathrm{~kg} / \mathrm{m}^{2}$ and singleton pregnancy between $10^{+0}$ and $20^{+0}$ weeks gestation were eligible for enrolment. Women with a multiple pregnancy, or with type 1 or 2 diabetes diagnosed prior to pregnancy, or who were unable to provide informed consent were ineligible.

\section{Trial entry}

All women presenting for antenatal care had their height and weight measured and their BMI calculated at the first antenatal appointment. Eligible women were presented with written information, and were encouraged to discuss participation with their primary support person.

\section{Randomisation, masking and group allocation}

Randomisation occurred by telephoning the central randomisation service, which utilised a computer-generated schedule, with balanced variable blocks. Stratification occurred for parity ( 0 versus $\geq 1$ ), BMI at antenatal booking ( 25 to $29.9 \mathrm{~kg} / \mathrm{m}^{2}$ versus $\geq 30 \mathrm{~kg} / \mathrm{m}^{2}$ ), and collaborating centre. Women were randomised and allocated to either 'Lifestyle Advice' or 'Standard Care'.

\section{Nested randomised trial}

Between January 2010 and September 2011, we conducted a nested randomised trial, in which women who were randomised to the Lifestyle Advice group underwent further randomisation to receive either written and verbal information about physical activity (Lifestyle Advice Group), or to additionally be invited to participate in a targeted, supervised walking group (Walking group).

\section{Treatment schedules \\ Lifestyle Advice group}

Women randomised to receive Lifestyle Advice participated in a comprehensive dietary and lifestyle intervention over the course of their pregnancy, which included a combination of dietary, physical activity and behavioural strategies, delivered by a research dietician and trained research assistants [42]. Within 2 weeks of randomisation, the women attended a planning session with a research dietician, during which a detailed dietary and physical activity history was obtained.

Women were provided with dietary advice consistent with current Australian standards [43]: to maintain a balance of carbohydrates, fat and protein; to reduce intake of foods high 
in refined carbohydrates and saturated fats, while increasing intake of fibre; and to promote consumption of two servings of fruit, five servings of vegetables, and three servings of dairy each day [43]. Information was individualised, and included meal plans, healthy recipes that were quick to prepare, simple food substitutions (including reducing intake of sugarsweetened soft drinks and fruit juices, reducing added sugar and foods high in refined carbohydrates, and using low-fat alternatives), healthy snack and eating-out options, and guidelines for healthy food preparation.

Physical activity advice focused on the benefits of exercise in pregnancy, potential safety concerns relating to exercise during pregnancy, tips to increase incidental activity and walking, and promoting recreational, aerobic and strength-conditioning exercises that are appropriate during pregnancy [44].

Women were encouraged to set achievable goals for dietary and physical activity change, supported to make these lifestyle changes, and asked to self-monitor their progress through the use of a workbook. Women were encouraged to identify potential barriers to implementation of their dietary goals. Using these perceived barriers, women were assisted to problem-solve, and to develop individualised strategies to facilitate their successful implementation.

This information was reinforced during subsequent inputs provided by the research dietician (at 28 weeks' gestation) and trained research assistants (via telephone call at 22, 24, and 32 weeks' gestation and a face-face visit at 36 weeks' gestation).

\section{Walking group (nested randomised controlled trial)}

Women within the Lifestyle Advice group who had been further randomised to the Walking group were invited to participate in a targeted, supervised walking group, in addition to receiving the written and verbal information provided to all women assigned to the Lifestyle Advice group, as described above. The Walking group was designed to enable women to increase their level of physical activity through a simple form of exercise that could in future be performed without supervision, and that did not present a health risk to the pregnant woman or her unborn infant. Women were encouraged to participate three times per week, and to attend with a support person, under the guidance of a trained researcher.

There were three outdoor walking locations in the Adelaide metropolitan area, and two indoor walking locations in shopping centres. Indoor treadmill walking was provided at no cost as an alternative when the weather was not suitable for outdoor walking. Each walking session was designed to cover a distance of approximately $4.2 \mathrm{~km}$, and was of 40 minutes duration (including 5 minutes of general stretching and warming up, followed by 5 minutes of cooling down time at the end of each session). The intensity of walking was moderate, consistent with recommendations in pregnancy [45]. During the walking session, women were provided with the opportunity to discuss the importance and effects of physical activity during pregnancy, including the optimal amount and intensity of home exercise.

\section{Standard Care group}

Women randomised to receive Standard Care continued their pregnancy care according to local hospital guidelines, which did not include routine provision of advice related to diet, exercise, or gestational weight gain.

\section{Study endpoints: maternal diet}

The pre-specified endpoints related to maternal dietary intake were

- Food groups

- Macronutrient intake

- Micronutrient intake

- Healthy Eating Index (HEI)

- Dietary Glycaemic Load and Index

All women were asked to complete the Harvard Semi-quantitative Food Frequency questionnaire (the Willett questionnaire) at the time of study entry, at 28 and 36 weeks' gestational age, and at 4 months postpartum. The Willett questionnaire was developed in 1985 in the USA to measure the daily intake of nutrients from 126 food items, with an indication of standard portion size, divided into seven food groups [46], and has been validated for use during pregnancy [47], and in an Australian pregnancy setting [48]. Questions were asked about the relative frequency of consumption of specific food items, use of supplements, cooking methods used and addition of sugar to foods. An open-ended question allowed record of consumption of other foods, which were then categorised by the study investigators. Daily nutrient intakes were estimated by multiplying frequency responses by the nutrient compositions of the specified portion size of each food item according to Australian food composition tables [49], reflecting standard food fortification with both folate and iodine. To assess adherence to dietary recommendations, food and drink consumption was grouped into food groups as defined by the Australian Guide to Healthy Eating [43]. Foods that did not fit into the five core food groups were classed as 'non-core foods' being higher in fat, sugar and salt, and providing minimal nutrients [43].

For the questionnaire completed at study entry, women were asked to indicate how often on average they had consumed the amount of food during the past year. For the questionnaires completed at 28 and 36 weeks and postpartum, women were asked to indicate how often on average they had consumed the amount of food since the previous questionnaire was completed.

Micronutrient values were obtained from the Willett questionnaire and analysed as mean intakes, utilising the Food Works Nutrient Analysis Software Package (FoodWorks, v.7 Professional; Xyris Software 2012; Australia) incorporating Australian food composition tables. 
The 2005 HEI was used as an index of diet quality [50], consisting of 12 components, with a maximum score of 100. Total fruit (including 100\% juice), whole fruits, total vegetables, dark-green and orange vegetables and legumes, total grains and whole grains categories have a score out of 5; milk, meat and beans, oils, saturated fat and sodium have scores out of 10; and calories from solid fats, alcoholic beverages and added sugars (SoFAAS) have a score out of 20. A HEI score above 80 is considered good, a score between 50 and 80 needs improvement, and scores below 50 are considered poor. The HEI has been validated for use in a pregnant population [51].

GI values were obtained from the Willett questionnaire and analysed as mean intakes, utilising the Food Works Nutrient Analysis Software Package (as above), incorporating Australian food composition tables and published glycaemic index values. Dietary glycaemic index was determined as the sum of the glycaemic index for all carbohydrates consumed in the diet, with a proportional weighting to account for the relative contribution of each food.

\section{Study endpoints: maternal physical activity}

Women completed the Short Questionnaire to Assess Health-enhancing Physical Activity (SQUASH) [52] at trial entry, 28 and 36 weeks' gestation, and 4 months postpartum. The questionnaire comprises 11 questions evaluating time spent on different types of physical activity (including commuting, leisure, household and incidental, and work-related activities), has been validated against accelerometer data [52], and has been used during pregnancy [53] and the post-partum period [54]. An activity-specific intensity code from the Compendium of Physical Activities [55] was assigned to each reported activity, and a corresponding estimate of intensity in metabolic equivalent task units (METs) was determined, where 1 MET is equal to the energy expended during quiet sitting [55]. The number of minutes spent in each reported activity was multiplied by its MET intensity, and summed to calculate total daily energy expenditure. Because MET is a measure of intensity and rate of physical activity, the concept of the MET-minute was used to quantify the total amount of physical activity in a comparable way between individuals and across activities [55]. As the SQUASH questionnaire reports physical activity during an average week, MET-minutes per week (METs/week) were calculated as duration $(\mathrm{min}) \times$ frequency (days/week) of MET intensity.

\section{Analysis and reporting of results}

Analyses were performed on an intention-to-treat basis. Women were included in the analysis if they returned one or more 'valid' questionnaires, and did not withdraw consent to use their data or did not have a miscarriage, termination of pregnancy, or stillbirth. Diet questionnaires were considered invalid if over $25 \%$ of responses were missing or if total energy intake was unrealistic $(<4,500 \mathrm{~kJ}$ or $>20,000 \mathrm{~kJ}$ ) [56]. Physical activity questionnaires were considered invalid if the total hours of activity reported per week exceeded the number of hours in a week.

Outcomes were analysed using linear mixed effects models including treatment group, time, and their interaction, with adjustment made for the stratification variables centre, parity and BMI as fixed effects. Outcomes measured on different subjects were assumed to be independent, but outcomes measured on the same subject across the four time points were allowed to be correlated by specifying an unstructured covariance matrix for the error term. Baseline differences were allowed between treatment groups, as questionnaires were completed after women had been notified of their treatment group allocation, which may have influenced their responses. When the treatment $\times$ time interaction was significant, post hoc tests were performed to assess the effect of treatment group at each time point. When the interaction was not significant, it was removed from the model, and the main effect of treatment group was estimated. Exploratory analyses were also conducted to assess whether the effect of treatment varied by BMI category (overweight versus obese), by including an interaction between treatment group, time and BMI category (where the effect of treatment varied over time) or an interaction between treatment group and BMI category. Statistical significance was assessed at the two-sided $P<0.05$ level, and no adjustment was made for multiple comparisons. All analyses were performed using SAS software (v9.3; SAS Inc., Cary, NC, USA).

\section{Sample size}

The sample size of 2,180 women was pre-determined based on the primary outcome of the trial (large for gestational age infant) as reported previously [41].

\section{Results}

Between June 2008 and December 2011, we recruited and randomised 2,212 women, with 1,108 allocated to receive Lifestyle Advice and 1,104 Standard Care. There were 2,142 women (1,075 Lifestyle Advice; 1,067 Standard Care) available for inclusion in the analyses, after excluding women who withdrew consent to use their data (10 women) or had a miscarriage, termination of pregnancy or stillbirth (60 women) [41]. At least one valid dietary questionnaire [56] was received from 945 women $(87.9 \%)$ in the Lifestyle Advice group, and 928 women (87.0\%) in the Standard Care group. At least one valid physical activity questionnaire was received from 974 women (90.6\%) in the Lifestyle Advice group, and 950 women (89.0\%) in the Standard Care group who were included in the analyses (Figure 1). Baseline characteristics of the women who completed 


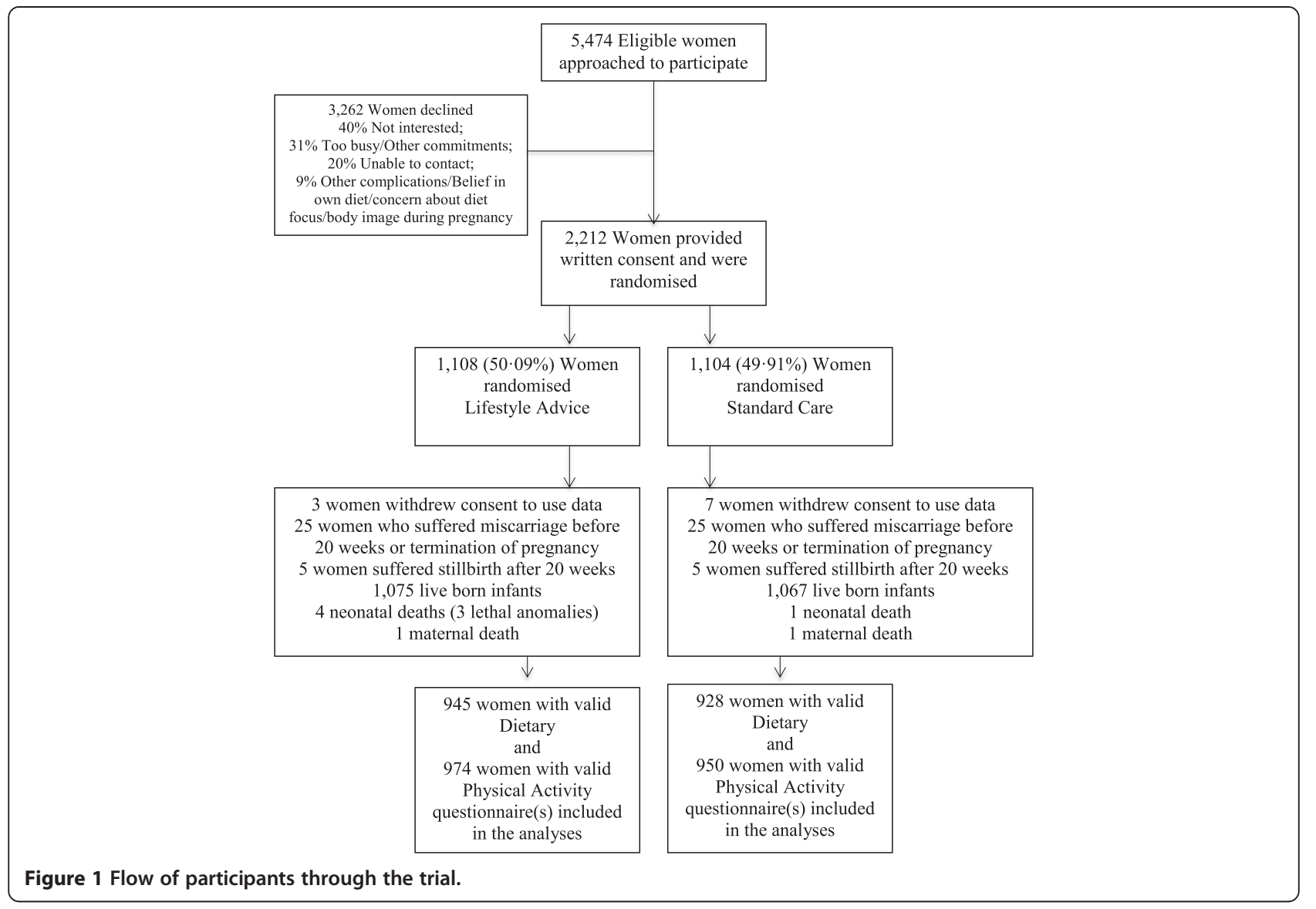

any questionnaires were similar between treatment groups (Table 1) and to the full randomised groups [41]. Number of questionnaires returned at each time point (study entry, 28 and 36 weeks' gestational age, and at 4 months postpartum) are shown in Additional file 1: Table S1.

\section{Macronutrient consumption and food groups}

There was no statistically significant difference identified in the average daily energy consumption between women receiving Lifestyle Advice and women receiving Standard Care (Table 2). However, women randomised to receive Lifestyle Advice demonstrated a significant increase in the number of servings per day of fruit overall and vegetables after trial entry, compared with women receiving Standard Care. Additionally, women receiving Lifestyle Advice increased their consumption of dietary fibre, while significantly reducing the percentage of their energy intake derived from saturated fats overall compared with women receiving Standard Care. There was no evidence to suggest that the intervention effect was modified by maternal BMI category (data not shown).

\section{Micronutrient consumption}

Women randomised to the Lifestyle Advice group demonstrated improvements in their dietary micronutrient intake. During pregnancy, women in the Lifestyle Advice group reported greater intake of calcium, potassium and vitamin $\mathrm{B}_{2}$, but this was not maintained postpartum (Table 3). These women also increased their consumption of vitamin A, vitamin $\mathrm{C}$ and folate overall, compared with women in the Standard Care group (Table 3). No significant changes were observed for other micronutrients. There was some evidence to suggest that the effect of the intervention on iodine, vitamin $\mathrm{E}$ and folate intake was modified by maternal BMI category (interaction $P<0.05$ in all cases), with overall intake significantly increased in obese but not overweight women randomised to the Lifestyle Advice group (data not shown).

\section{Healthy Eating Index}

Women randomised to receive Lifestyle Advice demonstrated significant improvement in their diet quality as measured by the HEI, at both 28 and 36 weeks' gestation, compared with women receiving Standard Care (Table 4). Specifically, women receiving Lifestyle Advice significantly increased their consumption of total fruit, whole fruit, and dark-green and orange vegetables and legumes, compared with women receiving Standard Care. With the exception of improved consumption of dark-green and orange vegetables and legumes, these 
Table 1 Demographic and clinical characteristics at trial entry

\begin{tabular}{|c|c|c|c|}
\hline Characteristic & Lifestyle advice $(n=974)$ & Standard care $(n=950)$ & Total $(n=1924)$ \\
\hline Maternal age, years ${ }^{a}$ & $29.4 \pm 5.4$ & $29.6 \pm 5.4$ & $29.5 \pm 5.4$ \\
\hline Gestational age at entry, weeks ${ }^{\mathrm{b}}$ & $14.3(12.0$ to 17.0$)$ & $14.3(12.0$ to 17.1$)$ & $14.3(12.0$ to 17.1$)$ \\
\hline \multicolumn{4}{|l|}{ Body mass index category, n (\%) } \\
\hline 25.0 to 29.9 & $410(42.1)$ & $421(44.3)$ & $831(43.2)$ \\
\hline 30.0 to 34.9 & $282(29.0)$ & $268(28.2)$ & $550(28.6)$ \\
\hline 35.0 to 39.9 & $180(18.5)$ & $155(16.3)$ & $335(17.4)$ \\
\hline$\geq 40.0$ & $102(10.5)$ & $106(11.2)$ & $208(10.8)$ \\
\hline Public patient, n (\%) & $954(97.9)$ & $927(97.6)$ & $1881(97.8)$ \\
\hline Caucasian, n (\%) & $883(90.7)$ & $866(91.2)$ & $1749(90.9)$ \\
\hline Smoker, n (\%) & $124(12.7)$ & $97(10.2)$ & $221(11.5)$ \\
\hline Nulliparous, n (\%) & $410(42.1)$ & $385(40.5)$ & $795(41.3)$ \\
\hline \multicolumn{4}{|c|}{ Index of Socio-economic Disadvantage, $n(\%)^{c}$} \\
\hline Unknown & $2(0.2)$ & $1(0.1)$ & $3(0.2)$ \\
\hline Quintile 1 (most disadvantaged) & $296(30.4)$ & $274(28.8)$ & $570(29.6)$ \\
\hline Quintile 2 & $231(23.7)$ & $236(24.8)$ & $467(24.3)$ \\
\hline Quintile 3 & $157(16.1)$ & $143(15.1)$ & $300(15.6)$ \\
\hline Quintile 4 & $138(14.2)$ & $151(15.9)$ & $289(15.0)$ \\
\hline Quintile 5 (least disadvantaged) & $150(15.4)$ & $145(15.3)$ & $295(15.3)$ \\
\hline
\end{tabular}

${ }^{\mathrm{a}}$ Mean \pm standard deviation.

${ }^{\mathrm{b}}$ Median (interquartile range).

Index of Socio-economic - disadvantage as measured by SEIFA (socioeconomic indexes for areas [57]).

changes were not maintained at four months postpartum. The intervention was not associated with changes in consumption of grains, meat and beans, oils, sodium, or caloric intake from SoFAAS. There was no evidence of modification of the intervention effect by maternal BMI category (data not shown).

\section{Glycaemic index and glycaemic load}

There were no statistically significant differences identified in dietary glycaemic load or dietary glycaemic index between women receiving Lifestyle Advice and women receiving Standard Care (Table 5). There was also no evidence of modification of the intervention effect by maternal BMI category (data not shown).

\section{Physical activity}

Women randomised to receive Lifestyle Advice demonstrated a significant overall improvement in total physical activity, compared with women receiving Standard Care (Table 6). This finding was driven by an overall increase in household activity, with some evidence of an increase in leisure activity also, and represented an additional 15 to 20 minutes brisk walking on most days of the week. Commuting and work-related activities were similar between groups and at each time point for women who engaged in these activities (data not shown). No changes in treatment effects over time were identified for any types of activity (Table 6). There was some evidence to suggest that the effect of the intervention was modified by maternal BMI category for total physical activity $(P=0.043)$, with women who were obese demonstrating the greatest increase in total physical activity (adjusted difference in means 617.20 MET-minutes/week; 95\% CI 238.48 to $995.92 ; P=0.001$ ).

\section{Nested randomised trial}

During the specified time period, 582 eligible women from the Lifestyle Advice group were further randomised, 287 to the Walking group, and 295 to the Lifestyle group. Baseline characteristics of the women who participated in the nested randomised trial are included in Additional file 2: Table S2 and were similar between treatment groups. There were 580 women (286 Walking group; 294 Lifestyle group) available for inclusion in the analyses, after 1 woman had a miscarriage, and 1 woman withdrew consent to utilise her data. At least 1 valid physical activity questionnaire was received from 257 women in the Walking group (89.9\%), and 269 women (91.5\%) in the Lifestyle group (Figure 2). At trial entry, the characteristics of the women included in the analysis were similar between treatment groups (data not shown).

Of the women randomised to the Walking group, $190(66 \%)$ subsequently declined to participate in the Walking group when contacted despite their initial 
Table 2 Food group and macronutrient consumption: between treatment group comparison ${ }^{\text {a }}$

\begin{tabular}{|c|c|c|c|c|c|c|}
\hline \multirow[t]{2}{*}{ Outcome } & \multirow[t]{2}{*}{ Time point } & \multirow{2}{*}{$\begin{array}{l}\text { Lifestyle advice } \\
(\mathrm{n}=945)^{\mathrm{b}}\end{array}$} & \multirow{2}{*}{$\begin{array}{l}\text { Standard } \\
\text { care }(n=928)^{b}\end{array}$} & \multirow{2}{*}{$\begin{array}{l}\text { Adjusted } \\
\text { treatment } \times \text { time } \\
\text { interaction } P \text {-value }\end{array}$} & \multicolumn{2}{|c|}{ Adjusted treatment effect } \\
\hline & & & & & $P$ & $95 \% \mathrm{Cl}$ \\
\hline \multirow[t]{4}{*}{ Total energy, $\mathrm{kJ}^{\mathrm{d}}$} & Trial entry & 8678.89 (2690.39) & $8501.40(2565.19)$ & 0.99 & 0.09 & $178.60(-26.56$ to 383.77$)$ \\
\hline & 28 weeks & $8772.33(2545.60)$ & $8675.26(2792.00)$ & & & \\
\hline & 36 weeks & $8667.72(2585.28)$ & $8568.86(2751.49)$ & & & \\
\hline & 4 months & $8763.08(2694.71)$ & $8628.89(2686.06)$ & & & \\
\hline \multirow{4}{*}{$\begin{array}{l}\text { Breads and cereals, } \\
\text { servings/day }{ }^{d}\end{array}$} & Trial entry & $2.63(1.45)$ & $2.61(1.43)$ & 0.82 & 0.27 & $0.06(-0.04$ to 0.16$)$ \\
\hline & 28 weeks & $2.65(1.34)$ & $2.59(1.42)$ & & & \\
\hline & 36 weeks & $2.66(1.33)$ & $2.59(1.42)$ & & & \\
\hline & 4 months & $2.58(1.39)$ & $2.51(1.37)$ & & & \\
\hline \multirow[t]{4}{*}{ Dairy, servings/day } & Trial entry & $2.05(1.34)$ & $2.21(1.52)$ & 0.002 & 0.02 & $-0.17(-0.30$ to -0.03$)$ \\
\hline & 28 weeks & $2.30(1.24)$ & $2.24(1.39)$ & & 0.09 & $0.12(-0.02$ to 0.25$)$ \\
\hline & 36 weeks & $2.42(1.42)$ & $2.33(1.40)$ & & 0.24 & $0.09(-0.06$ to 0.24$)$ \\
\hline & 4 months & $2.28(1.36)$ & $2.24(1.42)$ & & 0.56 & $0.05(-0.11$ to 0.21$)$ \\
\hline \multirow[t]{4}{*}{ Fruit, servings/day ${ }^{d}$} & Trial entry & $2.67(2.07)$ & $2.48(1.63)$ & 0.44 & 0.002 & 0.21 (0.08 to 0.35 ) \\
\hline & 28 weeks & $2.70(1.62)$ & $2.43(1.74)$ & & & \\
\hline & 36 weeks & $2.56(1.47)$ & $2.34(1.67)$ & & & \\
\hline & 4 months & $2.24(1.64)$ & $2.11(1.56)$ & & & \\
\hline \multirow{4}{*}{$\begin{array}{l}\text { Meat and legumes, } \\
\text { servings/day }{ }^{d}\end{array}$} & Trial entry & $2.14(1.03)$ & $2.10(0.94)$ & 0.67 & 0.14 & $0.06(-0.02$ to 0.14$)$ \\
\hline & 28 weeks & $2.17(1.08)$ & $2.10(0.97)$ & & & \\
\hline & 36 weeks & $2.14(0.91)$ & $2.08(1.05)$ & & & \\
\hline & 4 months & $2.30(0.95)$ & $2.29(1.08)$ & & & \\
\hline \multirow[t]{4}{*}{ Vegetables, servings/day } & Trial entry & $4.96(2.64)$ & $4.82(2.57)$ & 0.03 & 0.30 & $0.13(-0.12$ to 0.38$)$ \\
\hline & 28 weeks & $5.16(2.68)$ & $4.71(2.37)$ & & 0.0002 & 0.47 (0.22 to 0.72$)$ \\
\hline & 36 weeks & $4.87(2.54)$ & $4.51(2.65)$ & & 0.003 & $0.40(0.13$ to 0.67$)$ \\
\hline & 4 months & $5.63(3.12)$ & $5.24(2.62)$ & & 0.003 & 0.50 (0.17 to 0.82$)$ \\
\hline \multirow{4}{*}{$\begin{array}{l}\text { Non-core group } \\
\text { foods, servings/day }\end{array}$} & Trial entry & $7.51(3.81)$ & $7.27(3.61)$ & 0.01 & 0.10 & $0.29(-0.06$ to 0.65$)$ \\
\hline & 28 weeks & $6.84(3.24)$ & $7.14(3.41)$ & & 0.17 & $-0.24(-0.58$ to 0.10$)$ \\
\hline & 36 weeks & $6.86(3.54)$ & $6.96(3.24)$ & & 0.72 & $-0.06(-0.41$ to 0.28$)$ \\
\hline & 4 months & $8.15(3.69)$ & $7.95(3.76)$ & & 0.41 & $0.17(-0.24$ to 0.59$)$ \\
\hline \multirow[t]{4}{*}{ Alcohol, g } & Trial entry & $2.25(5.21)$ & $2.48(6.47)$ & 0.59 & 0.20 & $0.07(-0.03$ to 0.17$)$ \\
\hline & 28 weeks & $0.34(1.35)$ & $0.25(0.86)$ & & & \\
\hline & 36 weeks & $0.31(1.42)$ & $0.27(1.06)$ & & & \\
\hline & 4 months & $2.27(4.04)$ & $2.18(4.92)$ & & & \\
\hline \multirow[t]{4}{*}{ Dietary fibre, $g^{d}$} & Trial entry & $32.39(12.91)$ & $31.64(12.43)$ & 0.16 & 0.002 & 1.55 (0.55 to 2.56$)$ \\
\hline & 28 weeks & $33.75(12.39)$ & $31.88(12.42)$ & & & \\
\hline & 36 weeks & $32.78(11.80)$ & $30.93(12.89)$ & & & \\
\hline & 4 months & $34.09(13.61)$ & $32.50(12.68)$ & & & \\
\hline \multirow[t]{4}{*}{ Carbohydrates, $g^{d}$} & Trial entry & $255.27(90.54)$ & $246.38(83.50)$ & 0.69 & 0.06 & $6.55(-0.19$ to 13.29$)$ \\
\hline & 28 weeks & $258.11(82.97)$ & $255.89(93.44)$ & & & \\
\hline & 36 weeks & 253.61 (85.76) & $251.43(90.66)$ & & & \\
\hline & 4 months & 247.86 (89.54) & $243.25(88.71)$ & & & \\
\hline \multirow{2}{*}{$\begin{array}{l}\text { Percentage energy } \\
\text { from carbohydrates }\end{array}$} & Trial entry & $46.85(5.97)$ & $46.22(5.59)$ & 0.23 & 0.39 & $0.19(-0.24$ to 0.62$)$ \\
\hline & 28 weeks & $46.96(5.33)$ & $46.89(5.30)$ & & & \\
\hline
\end{tabular}


Table 2 Food group and macronutrient consumption: between treatment group comparison ${ }^{\mathrm{a}}$ (Continued)

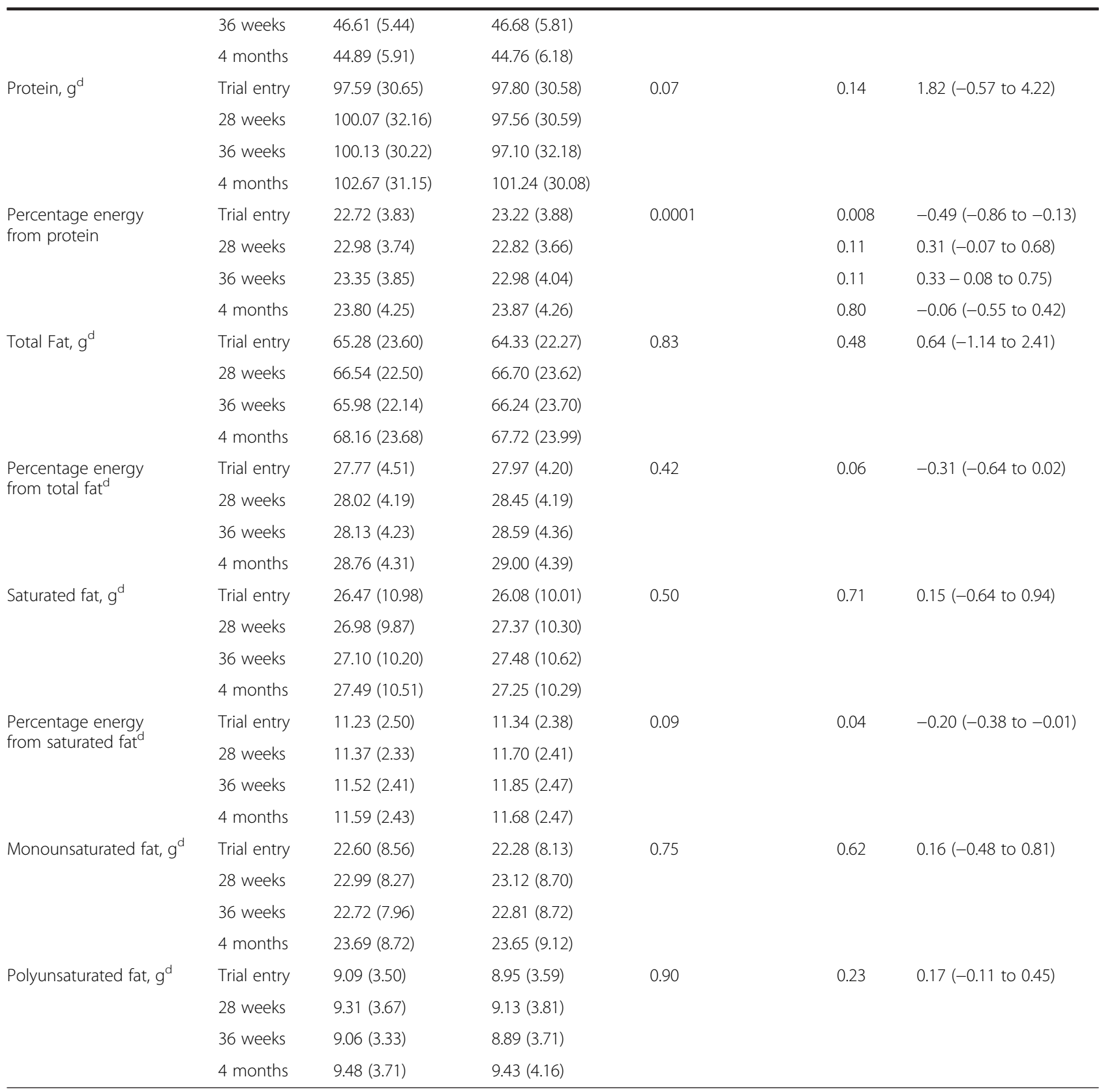

${ }^{a}$ Values are mean \pm SD and treatment effects are differences in means (with $95 \%$ confidence interval and $P$-value) by time point estimated from a linear mixed effects model including treatment, time and treatment $\times$ time, adjusted for centre, parity and BMI.

${ }^{b}$ Includes women who had a live birth, and who answered one or more questionnaires; excludes questionnaires with $>25 \%$ missing responses, or where there was an unrealistic energy intake reported $(<4,500$ or $>20,000 \mathrm{~kJ})$.

'Where the treatment $\times$ time interaction was not statistically significant, it was dropped from the model.

${ }^{d}$ Values are mean \pm SD and treatment effects are differences in means (with $95 \%$ confidence interval and $P$-value) across all time points estimated from a linear mixed effects model including treatment and time, adjusted for centre, parity and BMI.

consent, 57 (20\%) booked but subsequently did not attend a walking session, and 40 (14\%) attended at least one session. The median number of sessions attended was 2 (interquartile range 1 to 7 ). In women who participated in the Walking group, no serious adverse effects of exercise (including syncope, chest pain, shortness of breath, vaginal bleeding or miscarriage) were identified.

Women further randomised to the Walking group demonstrated no significant difference in total physical activity compared with women in the Lifestyle group (Table 7). Commuting, housework and work-related 
Table 3 Dietary micronutrient consumption: between treatment group comparison ${ }^{\text {a }}$

\begin{tabular}{|c|c|c|c|c|c|c|}
\hline \multirow[t]{2}{*}{ Outcome } & \multirow[t]{2}{*}{ Time point } & \multirow{2}{*}{$\begin{array}{l}\text { Lifestyle advice } \\
(\mathrm{n}=945)^{\mathrm{b}}\end{array}$} & \multirow{2}{*}{$\begin{array}{l}\text { Standard } \\
\text { care }(n=928)^{b}\end{array}$} & \multirow{2}{*}{$\begin{array}{l}\text { Adjusted } \\
\text { treatment } \times \text { time } \\
\text { interaction } P \text {-value }\end{array}$} & \multicolumn{2}{|c|}{ Adjusted treatment effect } \\
\hline & & & & & $P$ & $95 \% \mathrm{Cl}$ \\
\hline \multirow[t]{4}{*}{ Caffeine, $\mathrm{mg}^{\mathrm{d}}$} & Trial entry & $142.59(156.88)$ & $136.59(156.36)$ & 0.57 & 0.57 & $3.68(-8.90$ to 16.26$)$ \\
\hline & 28 weeks & $134.63(147.21)$ & $132.76(147.04)$ & & & \\
\hline & 36 weeks & $129.61(141.89)$ & $128.55(140.66)$ & & & \\
\hline & 4 months & $202.78(191.12)$ & $191.83(185.43)$ & & & \\
\hline \multirow[t]{4}{*}{ Sodium, $\mathrm{mg}^{\mathrm{d}}$} & Trial entry & $2713.21(1080.73)$ & $2644.16(1102.75)$ & 0.86 & 0.10 & $70.55(-13.71$ to 154.81$)$ \\
\hline & 28 weeks & $2684.04(1038.11)$ & $2651.08(1048.43)$ & & & \\
\hline & 36 weeks & $2704.91(1059.82)$ & $2620.33(1045.35)$ & & & \\
\hline & 4 months & $2822.92(1164.27)$ & $2759.30(1092.84)$ & & & \\
\hline \multirow[t]{4}{*}{ Calcium, mg } & Trial entry & $930.81(388.80)$ & $963.43(429.48)$ & 0.007 & 0.11 & $-32.10(-71.25$ to 7.04$)$ \\
\hline & 28 weeks & $1009.34(366.54)$ & $984.56(400.48)$ & & 0.04 & 40.73 (1.57 to 79.88$)$ \\
\hline & 36 weeks & $1031.14(421.66)$ & $1003.76(404.85)$ & & 0.15 & $31.99(-11.04$ to 75.02$)$ \\
\hline & 4 months & $1007.13(415.11)$ & $990.64(416.75)$ & & 0.37 & $21.26(-25.14$ to 67.67$)$ \\
\hline \multirow[t]{4}{*}{ Iron, $\mathrm{mg}^{\mathrm{d}}$} & Trial entry & $13.79(4.79)$ & $13.57(4.61)$ & 0.83 & 0.08 & $0.33(-0.04$ to 0.70$)$ \\
\hline & 28 weeks & $14.21(4.56)$ & $13.94(4.92)$ & & & \\
\hline & 36 weeks & $14.03(4.48)$ & $13.69(5.04)$ & & & \\
\hline & 4 months & $14.51(4.79)$ & $14.08(4.77)$ & & & \\
\hline \multirow[t]{4}{*}{ Zinc, mg ${ }^{d}$} & Trial entry & $11.71(3.69)$ & $11.71(3.56)$ & 0.08 & 0.11 & 0.23 (-0.06 to 0.52$)$ \\
\hline & 28 weeks & $12.14(3.70)$ & $11.82(3.70)$ & & & \\
\hline & 36 weeks & $12.12(3.68)$ & $11.75(3.90)$ & & & \\
\hline & 4 months & $12.36(3.74)$ & $12.12(3.62)$ & & & \\
\hline \multirow[t]{4}{*}{ Magnesium, mg ${ }^{\mathrm{d}}$} & Trial entry & 344.03 (116.89) & $342.67(116.44)$ & 0.11 & 0.06 & $9.07(-0.20$ to 18.33$)$ \\
\hline & 28 weeks & $356.11(110.62)$ & 344.98 (119.15) & & & \\
\hline & 36 weeks & $353.11(112.18)$ & $340.31(117.27)$ & & & \\
\hline & 4 months & $364.02(119.85)$ & 354.13 (118.78) & & & \\
\hline \multirow[t]{4}{*}{ Phosphorus, mg ${ }^{d}$} & Trial entry & $1586.85(497.80)$ & 1595.95 (515.48) & 0.08 & 0.16 & $28.14(-11.27$ to 67.56$)$ \\
\hline & 28 weeks & $1657.50(493.47)$ & $1618.65(509.91)$ & & & \\
\hline & 36 weeks & 1671.51 (516.33) & $1626.25(518.62)$ & & & \\
\hline & 4 months & 1689.35 (528.98) & $1655.95(514.58)$ & & & \\
\hline \multirow[t]{4}{*}{ Potassium, mg } & Trial entry & 3591.78 (1220.73) & $3570.31(1169.87)$ & 0.05 & 0.69 & 23.15 (-90.33 to 136.63$)$ \\
\hline & 28 weeks & 3723.05 (1129.40) & $3586.57(1223.47)$ & & 0.004 & 173.10 (54.97 to 291.23$)$ \\
\hline & 36 weeks & $3674.33(1131.83)$ & $3541.08(1185.20)$ & & 0.01 & 158.03 (38.14 to 277.92$)$ \\
\hline & 4 months & 3781.35 (1271.44) & 3657.89 (1165.91) & & 0.06 & $127.88(-4.96$ to 260.72$)$ \\
\hline \multirow[t]{4}{*}{ lodine, $\mu g^{d}$} & Trial entry & $204.05(108.94)$ & $205.81(105.00)$ & 0.37 & 0.38 & $3.54(-4.36$ to 11.44$)$ \\
\hline & 28 weeks & 210.93 (97.92) & 206.26 (96.36) & & & \\
\hline & 36 weeks & $215.94(101.27)$ & 209.86 (99.91) & & & \\
\hline & 4 months & $214.81(109.29)$ & $212.34(102.24)$ & & & \\
\hline \multirow{4}{*}{$\begin{array}{l}\text { Vitamin A Active } \\
\text { Equivalent, } \mu g^{d}\end{array}$} & Trial entry & 1475.35 (974.00) & $1404.15(752.52)$ & 0.16 & 0.003 & 110.40 (36.48 to 184.32$)$ \\
\hline & 28 weeks & 1605.54 (1323.79) & $1424.89(890.08)$ & & & \\
\hline & 36 weeks & $1462.83(821.57)$ & $1363.63(877.70)$ & & & \\
\hline & 4 months & $1658.00(1077.44)$ & $1539.68(852.02)$ & & & \\
\hline \multirow[t]{2}{*}{ Retinol, $\mu \mathrm{g}^{\mathrm{d}}$} & Trial entry & 366.23 (558.09) & 336.37 (311.97) & 0.34 & 0.33 & $18.56(-18.64$ to 55.75$)$ \\
\hline & 28 weeks & $422.55(1087.70)$ & $372.54(607.22)$ & & & \\
\hline
\end{tabular}


Table 3 Dietary micronutrient consumption: between treatment group comparison ${ }^{\text {a }}$ (Continued)

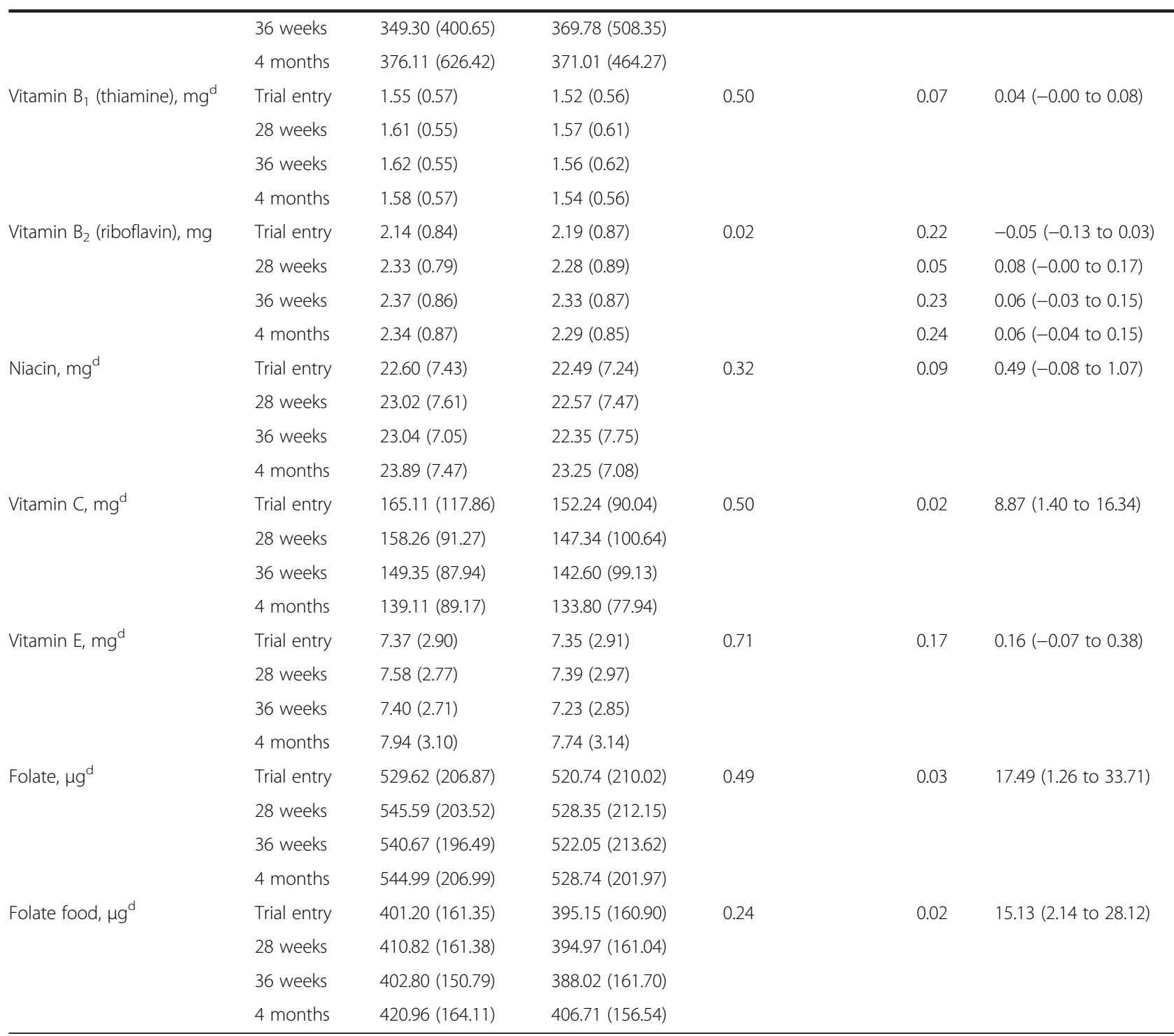

${ }^{\mathrm{a}}$ Values are mean \pm SD and treatment effects are differences in means (with $95 \%$ confidence interval and $P$-value) by time point estimated from a linear mixed effects model including treatment, time and treatment $\times$ time, adjusted for centre, parity and body mass index.

${ }^{b}$ Includes women who had a live birth, and who answered one or more questionnaires; excludes questionnaires with $>25 \%$ missing responses, or where there was an unrealistic energy intake reported $(<4,500$ or $>20,000 \mathrm{~kJ})$.

'Where the treatment $\times$ time interaction was not statistically significant, it was dropped from the model.

dValues are mean \pm SD and treatment effects are differences in means (with $95 \%$ confidence interval and $P$-value) across all time points estimated from a linear mixed effects model including treatment and time, adjusted for centre, parity and BMI.

activities were similar between groups. There was some evidence to suggest that treatment effects varied over time for leisure activities (interaction $P=0.04$ ), but no significant differences were identified between treatment groups at any time point in post hoc testing.

\section{Discussion}

Our randomised trial is the largest reported to date evaluating specific dietary and physical activity effects of an antenatal lifestyle intervention for women who are overweight or obese during pregnancy, utilising robust methodology, and is the first to compare differing intensities of provision of support for increasing physical activity. The findings indicate that provision of an intervention during pregnancy is effective in improving maternal diet. Specifically, our data suggest that intake of fibre, saturated fat, fruits and vegetables, micronutrient intake, and overall maternal diet quality, as measured by the HEI, improved following the intervention, in the absence of significant changes in energy intake. Although some changes in diet quality and micronutrient consumption were evident during pregnancy, the improvements 
Table 4 Healthy eating index: between treatment group comparison ${ }^{a}$

\begin{tabular}{|c|c|c|c|c|c|c|}
\hline \multirow[t]{2}{*}{ Outcome } & \multirow[t]{2}{*}{ Time point } & \multirow{2}{*}{$\begin{array}{l}\text { Lifestyle advice } \\
(\mathrm{n}=945)^{\mathrm{b}}\end{array}$} & \multirow{2}{*}{$\begin{array}{l}\text { Standard } \\
\text { care }(n=928)^{b}\end{array}$} & \multirow{2}{*}{$\begin{array}{l}\text { Adjusted } \\
\text { treatment } \times \text { time } \\
\text { interaction } P \text {-value }\end{array}$} & \multicolumn{2}{|c|}{ Adjusted treatment effect } \\
\hline & & & & & $P$ & $95 \% \mathrm{Cl}$ \\
\hline \multirow[t]{4}{*}{$\mathrm{HEl}$, range 0 to 100} & Trial entry & $72.11(7.71)$ & $72.80(7.07)$ & $<0.0001$ & 0.06 & $-0.67(-1.37$ to 0.03$)$ \\
\hline & 28 weeks & $73.35(6.62)$ & $71.86(7.01)$ & & $<0.0001$ & 1.58 (0.89 to 2.27 ) \\
\hline & 36 weeks & $72.95(6.82)$ & $71.17(7.69)$ & & $<0.0001$ & 1.77 (1.01 to 2.53$)$ \\
\hline & 4 months & $72.83(7.56)$ & $72.15(7.47)$ & & 0.41 & $0.35(-0.48$ to 1.18$)$ \\
\hline \multirow[t]{4}{*}{ Total fruit, range 0 to 5} & Trial entry & $4.50(1.02)$ & $4.48(1.03)$ & 0.003 & 0.567 & $0.03(-0.07$ to 0.13$)$ \\
\hline & 28 weeks & $4.63(0.89)$ & $4.42(1.11)$ & & 0.0001 & 0.20 (0.10 to 0.30$)$ \\
\hline & 36 weeks & $4.58(0.97)$ & $4.34(1.18)$ & & $<0.0001$ & 0.24 (0.13 to 0.35$)$ \\
\hline & 4 months & $4.27(1.23)$ & $4.11(1.33)$ & & 0.07 & $0.14(-0.01$ to 0.28$)$ \\
\hline \multirow[t]{4}{*}{ Whole fruit, range 0 to 5} & Trial entry & $4.56(1.09)$ & $4.57(1.05)$ & 0.0002 & 0.77 & $-0.01(-0.12$ to 0.09$)$ \\
\hline & 28 weeks & $4.68(0.94)$ & $4.50(1.15)$ & & 0.0003 & 0.19 (0.09 to 0.30$)$ \\
\hline & 36 weeks & $4.64(1.03)$ & $4.42(1.24)$ & & $<0.0001$ & 0.24 (0.12 to 0.35$)$ \\
\hline & 4 months & $4.43(1.18)$ & $4.35(1.24)$ & & 0.30 & $0.07(-0.06$ to 0.21$)$ \\
\hline \multirow[t]{4}{*}{ Total vegetables, range 0 to $5^{\mathrm{d}}$} & Trial entry & $4.86(0.58)$ & $4.88(0.50)$ & 0.06 & 0.12 & $0.03(-0.01$ to 0.06$)$ \\
\hline & 28 weeks & $4.91(0.44)$ & $4.88(0.48)$ & & & \\
\hline & 36 weeks & $4.88(0.49)$ & $4.81(0.62)$ & & & \\
\hline & 4 months & $4.94(0.31)$ & $4.89(0.45)$ & & & \\
\hline \multirow{4}{*}{$\begin{array}{l}\text { Dark-green and orange } \\
\text { Vegetables and legumes, } \\
\text { range } 0 \text { to } 5^{d}\end{array}$} & Trial entry & $4.76(0.76)$ & $4.72(0.84)$ & 0.12 & 0.0006 & 0.10 (0.04 to 0.16$)$ \\
\hline & 28 weeks & $4.82(0.64)$ & $4.73(0.78)$ & & & \\
\hline & 36 weeks & $4.76(0.77)$ & $4.64(0.93)$ & & & \\
\hline & 4 months & $4.89(0.46)$ & $4.78(0.75)$ & & & \\
\hline \multirow[t]{4}{*}{ Total grains, range 0 to $5^{d}$} & Trial entry & $3.88(0.93)$ & $3.89(0.91)$ & 0.24 & 0.55 & $-0.02(-0.09$ to 0.05$)$ \\
\hline & 28 weeks & $3.88(0.91)$ & $3.95(0.88)$ & & & \\
\hline & 36 weeks & $3.93(0.91)$ & $3.92(0.93)$ & & & \\
\hline & 4 months & $3.80(1.00)$ & $3.78(1.04)$ & & & \\
\hline \multirow[t]{4}{*}{ Whole grains, range 0 to $5^{d}$} & Trial entry & $0.71(0.88)$ & $0.71(0.83)$ & 0.23 & 0.14 & $0.05(-0.02$ to 0.11$)$ \\
\hline & 28 weeks & $0.74(0.86)$ & $0.67(0.83)$ & & & \\
\hline & 36 weeks & $0.82(0.90)$ & $0.71(0.91)$ & & & \\
\hline & 4 months & $0.81(0.87)$ & $0.78(0.88)$ & & & \\
\hline \multirow[t]{4}{*}{ Milk, range 0 to 10} & Trial entry & $6.54(2.80)$ & $6.98(2.82)$ & $<0.0001$ & 0.002 & $-0.42(-0.69$ to -0.16$)$ \\
\hline & 28 weeks & $7.37(2.61)$ & $7.15(2.70)$ & & 0.04 & 0.29 (0.01 to 0.56$)$ \\
\hline & 36 weeks & $7.48(2.49)$ & $7.34(2.69)$ & & 0.45 & $0.10(-0.17$ to 0.38$)$ \\
\hline & 4 months & $7.23(2.70)$ & $7.01(2.69)$ & & 0.28 & $0.17(-0.14$ to 0.48$)$ \\
\hline \multirow[t]{4}{*}{ Meat and beans, range 0 to $10^{d}$} & Trial entry & $9.59(1.20)$ & $9.61(1.07)$ & 0.24 & 0.67 & $0.02(-0.06$ to 0.10$)$ \\
\hline & 28 weeks & 9.59 (1.16) & $9.55(1.16)$ & & & \\
\hline & 36 weeks & $9.60(1.13)$ & $9.46(1.26)$ & & & \\
\hline & 4 months & $9.74(0.96)$ & $9.74(0.99)$ & & & \\
\hline \multirow[t]{4}{*}{ Oils, range 0 to $10^{d}$} & Trial entry & $5.48(3.19)$ & $5.45(3.25)$ & 0.24 & 0.15 & $0.18(-0.07$ to 0.42$)$ \\
\hline & 28 weeks & $5.50(3.17)$ & $5.27(3.18)$ & & & \\
\hline & 36 weeks & $5.42(3.27)$ & $4.99(3.25)$ & & & \\
\hline & 4 months & $5.69(3.18)$ & $5.46(3.26)$ & & & \\
\hline
\end{tabular}


Table 4 Healthy eating index: between treatment group comparison ${ }^{a}$ (Continued)

\begin{tabular}{|c|c|c|c|c|c|c|}
\hline \multirow[t]{4}{*}{ Saturated fat, range 0 to $10^{d}$} & Trial entry & $5.48(3.00)$ & $5.36(2.96)$ & 0.08 & 0.07 & $0.21(-0.02$ to 0.44$)$ \\
\hline & 28 weeks & $5.31(2.88)$ & $4.91(2.90)$ & & & \\
\hline & 36 weeks & $5.04(3.04)$ & $4.70(3.02)$ & & & \\
\hline & 4 months & $5.01(3.02)$ & $4.97(3.00)$ & & & \\
\hline \multirow[t]{4}{*}{ Sodium, range 0 to $10^{d}$} & Trial entry & $6.10(2.43)$ & $6.22(2.43)$ & 0.77 & 0.34 & $-0.09(-0.27$ to 0.10$)$ \\
\hline & 28 weeks & $6.28(2.42)$ & $6.27(2.32)$ & & & \\
\hline & 36 weeks & $6.10(2.44)$ & $6.28(2.38)$ & & & \\
\hline & 4 months & $5.80(2.63)$ & $5.91(2.46)$ & & & \\
\hline \multirow{4}{*}{$\begin{array}{l}\text { Calories from solid fats, } \\
\text { alcohol and added sugar } \\
\text { (SoFAAS), range } 0 \text { to } 20^{d}\end{array}$} & Trial entry & $15.64(3.79)$ & $15.94(3.60)$ & 0.150 & 0.56 & $-0.08(-0.33$ to 0.18$)$ \\
\hline & 28 weeks & $15.63(3.24)$ & $15.55(3.45)$ & & & \\
\hline & 36 weeks & $15.69(3.20)$ & $15.57(3.51)$ & & & \\
\hline & 4 months & $16.21(3.33)$ & $16.37(3.22)$ & & & \\
\hline
\end{tabular}

${ }^{a}$ Values are mean \pm SD and treatment effects are differences in means (with $95 \%$ confidence interval and $P$-value) by time point estimated from a linear mixed effects model including treatment, time and treatment $\times$ time, adjusted for centre, parity and BMI.

${ }^{b}$ Includes women who had a live birth, and who answered one or more questionnaires; excludes questionnaires with $>25 \%$ missing responses, or where there was an unrealistic energy intake reported $(<4,500$ or $>20,000 \mathrm{~kJ})$.

'Where the treatment $\times$ time interaction was not statistically significant, it was dropped from the model.

${ }^{d}$ Values are mean \pm SD and treatment effects are differences in means (with $95 \%$ confidence interval and $P$-value) across all time points estimated from a linear mixed effects model including treatment and time, adjusted for centre, parity and BMI.

noted were often not maintained at 4 months postpartum, and there were no differences identified in maternal dietary glycaemic load or index. There was little evidence to suggest that the effect of the intervention differed between overweight and obese women.

The findings of the LIMIT Trial also indicate that provision of a lifestyle intervention during pregnancy was effective in increasing total physical activity, largely through increasing household activity, approximately equivalent to an additional 15 to 20 minutes brisk walking on most days of the week, an effect that was more pronounced among obese women. Although women were provided with access to a structured walking group in the nested component of the trial, attendance was poor, with women preferring a less supervised approach to physical activity.

We have previously reported an $18 \%$ relative risk reduction in infant birth weight above $4 \mathrm{~kg}$ following the provision of an antenatal intervention for pregnant women who are overweight or obese [41]. This observed effect on infant birth weight appears to have been mediated by changes in maternal diet quality and physical activity, despite the fact that maternal gestational weight gain [41], total energy intake during pregnancy, and dietary GL, did not differ significantly between the two randomised groups.

Detailed dietary changes following antenatal interventions to women who are overweight or obese have been poorly reported to date. To our knowledge, the current randomised trial is one of the few studies presenting detailed macronutrient, micronutrient, food group, dietary quality, and glycaemic index or glycaemic load information in an overweight or obese pregnant population. There is evidence from non-pregnant populations that subtle differences in HEI may be associated with improvements in health and reduced complications associated with type 2 diabetes [58]. However, other studies report larger differences in diet quality, in association with changes in blood pressure and other measures of cardiometabolic disease, including cholesterol $[59,60]$. We previously identified a decline in maternal HEI over the duration of pregnancy, which was maintained into the postpartum period, and was positively correlated with socioeconomic status [14]. While the currently reported HEI scores are higher than those previously derived from a far smaller subgroup of participants [14], the trend towards a decline in diet quality across pregnancy and into the postpartum period was also evident for all the women receiving standard care.

Overall, the existing literature supports the positive effect of lifestyle interventions during pregnancy for women who are overweight or obese in improving a range of measures of dietary intake [40,61-63], even in the absence of changes in gestational weight gain and overall energy intake $[61,62]$. Specific dietary modifications reported include reduced consumption of saturated fats [40,61-63] and increased consumption of protein $[40,61,63]$. The currently reported findings are consistent with maternal total energy intake observed in other studies $[61,63]$, and although the percentage energy derived from fat was similar to that reported by Wolff and colleagues [63], it was lower than that reported by both Guelinckx [61] and Poston [40]. These differences 
Table 5 Glycaemic load and glycaemic index: between treatment group comparison ${ }^{a}$

\begin{tabular}{|c|c|c|c|c|c|c|}
\hline \multirow[t]{2}{*}{ Outcome } & \multirow[t]{2}{*}{ Time point } & \multirow{2}{*}{$\begin{array}{l}\text { Lifestyle advice } \\
(\mathrm{n}=945)^{\mathrm{b}}\end{array}$} & \multirow{2}{*}{$\begin{array}{l}\text { Standard } \\
\text { care }(n=928)^{b}\end{array}$} & \multirow{2}{*}{$\begin{array}{l}\text { Adjusted treatment } \times \text { time } \\
\text { interaction } P \text {-value }{ }^{c}\end{array}$} & \multicolumn{2}{|c|}{ Adjusted treatment effect } \\
\hline & & & & & $P$ & $95 \% \mathrm{Cl}$ \\
\hline \multirow[t]{4}{*}{ Glycaemic load } & Trial entry & $129.46(47.84)$ & $124.92(45.07)$ & 0.45 & 0.15 & $2.62(-0.94$ to 6.18$)$ \\
\hline & 28 weeks & $130.10(44.55)$ & $129.86(50.67)$ & & & \\
\hline & 36 weeks & $126.96(44.90)$ & $127.12(48.60)$ & & & \\
\hline & 4 months & $123.56(47.92)$ & $121.86(47.71)$ & & & \\
\hline \multirow[t]{4}{*}{ Glycaemic index } & Trial entry & $50.57(3.65)$ & $50.51(3.59)$ & 0.17 & 0.10 & $-0.22(-0.48$ to 0.04$)$ \\
\hline & 28 weeks & $50.19(3.36)$ & $50.48(3.45)$ & & & \\
\hline & 36 weeks & $49.90(3.47)$ & $50.32(3.65)$ & & & \\
\hline & 4 months & 49.55 (3.92) & $49.71(4.17)$ & & & \\
\hline
\end{tabular}

${ }^{a}$ Values are mean \pm SD and treatment effects are differences in means (with $95 \%$ confidence interval and $P$-value) across all time points estimated from a linear mixed effects model including treatment and time, adjusted for centre, parity and BMI.

${ }^{b}$ Includes women who had a live birth, and who answered one or more questionnaires; excludes questionnaires with $>25 \%$ missing responses, or where there was an unrealistic energy intake reported $(<4,500$ or $>20,000 \mathrm{~kJ})$.

'Where the treatment $\times$ time interaction was not statistically significant, it was dropped from the model.

may reflect variations in baseline characteristics, with the LIMIT cohort of women being predominantly of white ethnicity, and having lower mean BMI at trial entry.

The developmental over-nutrition hypothesis (also termed the Pedersen Hypothesis) was first proposed in
1954 [64] in an attempt to explain the relationship between maternal diabetes during pregnancy and fetal overgrowth, principally increased adiposity. Under this hypothesis, maternal hyperglycaemia is associated with increased placental transfer of glucose, resulting in

Table 6 Self-reported physical activity: between treatment group comparison ${ }^{a}$

\begin{tabular}{|c|c|c|c|c|c|c|}
\hline \multirow[t]{2}{*}{ Outcome } & \multirow[t]{2}{*}{ Time point } & \multirow{2}{*}{$\begin{array}{l}\text { Lifestyle advice } \\
(\mathrm{n}=974)^{\mathrm{b}}\end{array}$} & \multirow{2}{*}{$\begin{array}{l}\text { Standard care } \\
(\mathrm{n}=950)^{\mathrm{b}}\end{array}$} & \multirow{2}{*}{$\begin{array}{l}\text { Adjusted treatment } \times \text { time } \\
\text { interaction } P \text {-value }\end{array}$} & \multicolumn{2}{|c|}{ Adjusted treatment effect } \\
\hline & & & & & $P$ & $95 \% \mathrm{Cl}$ \\
\hline \multirow[t]{4}{*}{ Commuting activity $^{d}$} & Trial entry & $286.15(386.14)$ & $245.40(277.01)$ & 0.56 & 0.55 & $11.83(-26.75$ to 50.42$)$ \\
\hline & 28 weeks & $234.95(234.09)$ & $219.74(226.69)$ & & & \\
\hline & 36 weeks & $212.05(257.66)$ & $228.88(314.25)$ & & & \\
\hline & 4 months & 309.87 (331.10) & $330.50(422.89)$ & & & \\
\hline \multirow[t]{4}{*}{ Leisure activity } & Trial entry & $1081.25(1423.50)$ & $1022.28(1282.32)$ & 0.22 & 0.06 & $79.33(-2.09$ to 160.75$)$ \\
\hline & 28 weeks & $1016.04(1310.73)$ & $862.28(1092.86)$ & & & \\
\hline & 36 weeks & 788.66 (961.96) & $777.53(900.00)$ & & & \\
\hline & 4 months & $1281.07(1303.30)$ & $1163.67(1249.04)$ & & & \\
\hline \multirow[t]{4}{*}{ Household activity } & Trial entry & $3290.48(3139.01)$ & $3148.30(3093.46)$ & 0.59 & 0.01 & 265.60 (61.36 to 469.84$)$ \\
\hline & 28 weeks & $3229.92(3066.10)$ & $2988.91(2961.08)$ & & & \\
\hline & 36 weeks & $3158.49(2954.16)$ & $2813.98(2934.20)$ & & & \\
\hline & 4 months & $4756.43(3831.12)$ & $4677.16(3881.09)$ & & & \\
\hline \multirow[t]{4}{*}{ Work activity ${ }^{d}$} & Trial entry & $4697.83(3093.41)$ & 4405.76 (2818.43) & 0.40 & 0.52 & $80.85(-163.12$ to 324.83$)$ \\
\hline & 28 weeks & $4326.30(2707.53)$ & $4279.65(2660.85)$ & & & \\
\hline & 36 weeks & $4032.73(2484.61)$ & $4059.23(2593.77)$ & & & \\
\hline & 4 months & $3041.02(2505.86)$ & 3204.85 (2706.89) & & & \\
\hline \multirow[t]{4}{*}{ Total activity } & Trial entry & $7587.63(4573.52)$ & $7259.93(4145.34)$ & 0.99 & 0.01 & 359.76 (74.87 to 644.65$)$ \\
\hline & 28 Weeks & $7010.32(3950.39)$ & $6742.48(3836.85)$ & & & \\
\hline & 36 Weeks & $5819.82(3954.63)$ & $5518.10(3844.79)$ & & & \\
\hline & 4 Months & $6530.19(4336.80)$ & $6317.00(4498.15)$ & & & \\
\hline
\end{tabular}

Values are mean \pm SD and treatment effects are differences in means (with $95 \%$ confidence interval and $P$-value) across all time points estimated from a linear mixed effects model including treatment and time, adjusted for centre, parity and BMI.

${ }^{b}$ Includes women who had a live birth, and who answered one or more questionnaires; excludes questionnaires where the total hours of activity per week reported exceeded the number of hours in a week.

'Where the treatment $\times$ time interaction was not statistically significant, it was dropped from the model.

${ }^{\mathrm{d}}$ Where women participated in these activities. 


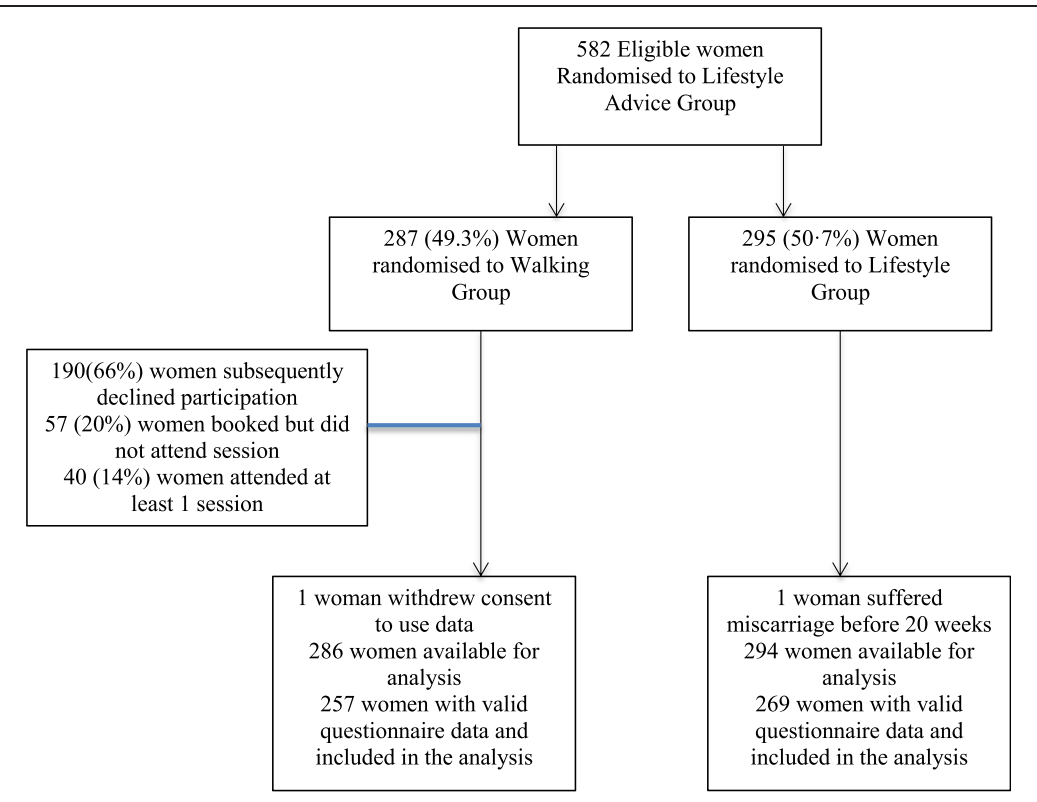

Figure 2 Flow of participants through the nested randomised trial.

fetal hyperglycaemia and increased insulin production, with the resultant effect being an increase in insulinmediated fetal growth. More recently, the hypothesis has been expanded to recognise the potential metabolic impact of maternal obesity [65], which shares a similar metabolic milieu, characterised by insulin resistance, hyperglycaemia, hyperlipidaemia and a low-grade state of chronic inflammation, which in turn has been documented to influence the availability and transfer of nutrients to the developing fetus [65].

The findings of the LIMIT Trial did not identify differences in maternal dietary glycaemic index or glycaemic load following antenatal lifestyle intervention, which is in contrast to other reports in the literature $[22,40]$. The effects of maternal dietary glycaemic index on pregnancy outcomes generally, and measures of fetal and neonatal growth more specifically, are uncertain. Although some studies have identified an association between maternal consumption of a low glycaemic index diet and reduced gestational weight gain [22,23], lower infant birth weight [24] and reduced neonatal adiposity as measured by thigh circumference [66], these findings are not universal, with others reporting no evidence of effect on infant birth weight $[23,25-27,40]$.

The contribution to fetal growth of other fuel substrates, including free fatty acids, triglycerides and amino acids, has also been recognised [64]. Fatty acids may be of importance as a fuel substrate for obese pregnant women, who have demonstrated increased reliance on lipid metabolism [67] in order to meet the energy requirements of pregnancy, which are only minimally accounted for by changes in dietary energy intake [68]. This is of particular relevance, given the currently reported findings of increased consumption of dietary fibre and reduced saturated fat intake, both of which could plausibly improve maternal insulin resistance [69] and contribute to our previously reported reduction in high infant birth weight following antenatal dietary and physical activity advice [41]. Furthermore, relatively modest changes in nutrient consumption and diet quality may directly affect clinical outcomes during pregnancy, particularly fetal and early infant growth. Reports in the literature indicate that maternal consumption of a diet high in polyunsaturated fatty acids is associated with a reduction in early childhood adiposity as measured by skinfold thickness [70], and is predictive of fat mass determined by dual energy $\mathrm{X}$-ray absorptiometry at the ages of 4 and 6 years [71]. Together with our findings, these reports highlight the potential impact of relatively modest changes in maternal diet quality on in utero growth, birth weight and future childhood adiposity.

There is a lack of consensus as to the most appropriate tool to assess physical activity, both in the general population, and more specifically during pregnancy [72]. Although physical activity questionnaires are a cost-effective method of assessment, particularly for use in large-scale studies, concerns have been raised about them over-estimating activity [73]. The use of pedometers and accelerometers has been advocated as a more objective tool, although these are not without their limitations, including poor measurement of upper body movement and stationary exercise [72]. Furthermore, the two methods do not appear interchangeable, particularly for overweight and obese pregnant women, with poorly reported correlation in step counts for any individual [74]. 
Table 7 Self-reported physical activity of participants in nested randomised trial: between treatment group comparison ${ }^{a}$

\begin{tabular}{|c|c|c|c|c|c|c|}
\hline \multirow[t]{2}{*}{ Outcome } & \multirow{2}{*}{$\begin{array}{l}\text { Time } \\
\text { point }\end{array}$} & \multirow{2}{*}{$\begin{array}{l}\text { Walking group } \\
(n=257)^{6}\end{array}$} & \multirow{2}{*}{$\begin{array}{l}\text { Information } \\
\text { only }(n=269)^{b}\end{array}$} & \multirow{2}{*}{$\begin{array}{l}\text { Adjusted treatment } \times \text { time } \\
\text { interaction } P \text {-value }^{c}\end{array}$} & \multicolumn{2}{|c|}{ Adjusted treatment effect } \\
\hline & & & & & $P$ & $95 \% \mathrm{Cl}$ \\
\hline \multirow[t]{4}{*}{${\text { Commuting } \text { activity }^{d}}$} & Trial entry & $227.30(281.27)$ & $240.47(243.97)$ & 0.24 & 0.63 & $17.41(-54.57$ to 89.39$)$ \\
\hline & 28 weeks & $218.05(176.55)$ & $200.32(287.47)$ & & & \\
\hline & 36 weeks & $292.52(366.32)$ & $185.01(178.98)$ & & & \\
\hline & 4 months & $248.44(263.20)$ & $390.00(512.82)$ & & & \\
\hline \multirow[t]{4}{*}{ Leisure activity ${ }^{\mathrm{e}}$} & Trial entry & $1048.02(1311.53)$ & $877.42(1146.34)$ & 0.04 & 0.11 & $174.72(-41.93$ to 391.38$)$ \\
\hline & 28 weeks & $1048.30(1248.43)$ & $911.11(1212.73)$ & & 0.36 & $108.50(-125.45$ to 342.44$)$ \\
\hline & 36 weeks & $796.16(1011.25)$ & 727.39 (810.12) & & 0.67 & $52.10(-188.17$ to 292.38$)$ \\
\hline & 4 months & $1178.16(1071.98)$ & $1374.64(1411.67)$ & & 0.08 & $-236.04(-503.44$ to 31.37$)$ \\
\hline \multirow[t]{4}{*}{ Household activity } & Trial entry & 3437.45 (3353.79) & $2961.20(2924.20)$ & 0.19 & 0.16 & 294.44 ( -114.88 to 703.76$)$ \\
\hline & 28 weeks & $3441.23(3085.54)$ & $2697.92(2732.72)$ & & & \\
\hline & 36 weeks & $3208.16(3005.22)$ & $2951.82(3111.69)$ & & & \\
\hline & 4 months & $4862.53(4204.93)$ & $4672.32(3766.02)$ & & & \\
\hline \multirow[t]{4}{*}{ Work-related activity ${ }^{d}$} & Trial entry & $4440.89(2743.25)$ & 4888.99 (3130.39) & 0.19 & 0.26 & $-259.57(-710.22$ to 191.08$)$ \\
\hline & 28 weeks & $4121.12(2359.13)$ & $4409.20(2735.41)$ & & & \\
\hline & 36 weeks & $3512.04(1852.27)$ & $4035.94(2274.21)$ & & & \\
\hline & 4 months & $3454.71(2619.25)$ & 3144.64 (2212.72) & & & \\
\hline \multirow[t]{4}{*}{ Total activity } & Trial entry & 7524.07 (4657.16) & $7311.45(4318.89)$ & 0.75 & 0.40 & 247.31 ( -332.35 to 826.98$)$ \\
\hline & 28 weeks & 7169.05 (3823.28) & $6564.51(3898.19)$ & & & \\
\hline & 36 weeks & $5888.77(3688.15)$ & $5479.91(4066.69)$ & & & \\
\hline & 4 months & $6526.84(4637.30)$ & 6641.77 (4494.63) & & & \\
\hline
\end{tabular}

\footnotetext{
${ }^{a}$ Values are mean \pm SD and treatment effects are differences in means (with $95 \%$ confidence interval and $P$-value) across all time points estimated from a linear mixed effects model including treatment and time, adjusted for centre, parity and BMI.

bIncludes women who had a live birth, and who answered one or more questionnaires; excludes questionnaires where the total hours of activity per week reported exceeded the number of hours in a week.

'Where the treatment $\times$ time interaction was not statistically significant, it was dropped from the model.

${ }^{\mathrm{d}}$ Where women participated in these activities.

eValues are mean \pm SD and treatment effects are differences in means (with 95\% confidence interval and P-value) by time point estimated from a linear mixed effects model including treatment, time and treatment $\times$ time, adjusted for centre, parity and BMI.
}

The published literature consistently reports a reduction in physical activity as pregnancy advances [39], particularly among women who are overweight or obese [40] compared with lean women [38,39]. Reports suggest that domestic and childcare activities constitute up to $50 \%$ of total energy expenditure and activity during pregnancy $[75,76]$, increasing to $65 \%$ in women who are obese [77]. It is therefore important that questionnaires include this activity category [75], particularly as other assessment measures, including both pedometers and accelerometers, are poor at identifying low-intensity activity [72].

A potential limitation of our trial is the reliance on self-reported questionnaire assessment of both dietary intake and physical activity. However, the purpose was to compare the effects of an antenatal intervention with standard care, and more detailed assessments of either dietary intake or physical activity were not considered feasible, given the sample size involved and the multiple time points assessed. A general concern with dietary and physical activity studies, particularly those relying on self-completed questionnaires, relates to the potential for recall bias, which may be differentially evident according to treatment group allocation. Even though women were asked about their dietary intake in the past 12 months at the time of trial entry, it is possible that the baseline assessment of both dietary intake and physical activity were influenced by knowledge of treatment group allocation. Although there was a fall-off in questionnaire response rates over pregnancy and the postpartum period, the proportion of women contributing data to the analyses was high. Furthermore, the women included in the analysis had similar baseline characteristics to, and can therefore be considered representative of, the complete randomised groups [41].

It is possible that women in the intervention group modified their self-reported dietary intake and physical activity following notification of the treatment group in order to provide 'desirable' answers and those that would be subsequently consistent with the content of 
the intervention sessions. However, if this were the case, we would have anticipated changes also to be reported in the consumption of refined carbohydrates and sugarsweetened beverages, which was not observed. We observed an increase in reported physical activity among women in the intervention group, which was consistent across all time points, including trial entry. This may reflect variation in the timing of completion of the trial entry questionnaire, with women randomised to the Lifestyle Advice group potentially increasing their activity in the period between randomisation and questionnaire return (up to 10 days), prior to attendance for their first intervention session. It may also reflect a chance occurrence, particularly because, although dietary questionnaires were completed within the same time period, no baseline differences in dietary intake measures were observed between the two treatment groups. True differences in physical activity of this magnitude between treatment groups at trial entry are unlikely, given our large sample size and the degree of balance achieved for other baseline characteristics.

\section{Conclusions}

To date, there has been a lack of detailed information from randomised trials outlining specific effects on maternal diet and physical activity, following an antenatal intervention for women who are overweight or obese. While our results indicate that provision of an antenatal dietary and lifestyle intervention is effective in improving maternal diet quality, food group, macronutrient and micronutrient intake, and physical activity during pregnancy, many of these improvements were not maintained at 4 months postpartum, highlighting the need for additional interventions during this important period of adjustment for women and their families.

We consider the observed changes in diet quality and physical activity during pregnancy, although modest, to be of clinical significance, given our reported findings of a reduced risk of infant birth weight above $4 \mathrm{~kg}$ for pregnant women who are overweight or obese [41], and such changes are likely to be far more achievable from a public health perspective than more restrictive approaches to limiting gestational weight gain. It will therefore be important to continue to follow up the infants born to women who participated in this trial to evaluate the longer-term health effects of the changes observed in maternal diet and physical activity achieved during pregnancy, particularly in relation to subsequent childhood obesity.

\section{Additional files}

Additional file 1: Table S1. Questionnaire response by time point.
Additional file 2: Table S2. Demographic and clinical characteristics at trial entry of participants in nested randomised trial.

\section{Competing interests}

The authors declare that they have no competing interests.

\section{Author contributions}

$J M D, C C, Z S, L N Y, A R D, R M G, L M, C A C, D T, A J M, G W, J A O$ and JSR are all members of the LIMIT randomised trial group. The primary investigator of the LIMIT randomised trial (JMD) prepared the initial draft of the manuscript, had full access to all of the study data, and takes responsibility for the integrity of the data and the accuracy of the data analysis. JMD and LNY were responsible for conducting the statistical analyses. All members of the LIMIT randomised trial group listed above were involved in the study concept and design of the trial, supervision of conduct of the trial, the acquisition of data, the analysis and interpretation of data and critical revision of the manuscript for important intellectual content, and all provided approval of the final submitted version.

\section{Acknowledgements}

The following individuals and institutions (except where indicated, in Adelaide, South Australia) participated in the LIMIT Trial:

Steering Group: JM Dodd (Chair), D Turnbull, A McPhee, RM Grivell, C Crowther, M Gillman (Obesity Prevention Program, and Harvard University, Boston, Massachusetts, USA), G Wittert, JA Owens, JS Robinson.

Co-ordinating Team: JM Dodd, A Deussen, RM Grivell, L Yelland, L Moran, C Cramp, A Newman, L Kannieappian, S Hendrijanto, M Kelsey, J Beaumont, C Danz, J Koch, A Webber, C Holst, K Robinson, S Zhang, V Ball, K Ball, H

Deussen, N Salehi, R Bartley, R Stafford-Green, S Ophel, M Cooney, M Szmeja, A Short, A Melrose, S Han, I Mohamad, L Chapple.

Statistical Analyses: L Yelland.

Serious Adverse Events Committee: RM Grivell, J Svigos, V Bhatia, N Manton. Writing Group: JM Dodd, D Turnbull, A McPhee, A Deussen, RM Grivell, L Yelland, C Crowther, G Wittert, JA Owens, JS Robinson.

Collaborating Hospitals (total number of women recruited from each site in parentheses). *Indicates named associate investigator for the NHMRC grant. - Flinders Medical Centre (South Australia) (669): J McGavigan*, R Bryce, S Coppi, C Fanning, G Hannah, M Ignacio, H Pollard, F Schmidt, Y Shinners. - Lyell McEwin Hospital (South Australia) (505): G Dekker*, S Kennedy-Andrews, R Beaven, J Niven, S Burgen, J Dalton, N Dewhurst, L Forst, V Mugg, C Will, H Stone. -Women's and Children's Hospital (South Australia) $(1,038)$ : JM Dodd, JS Robinson, A Deussen, C Crowther*, C Wilkinson*, H Purcell, J Wood, D Press, K Ralph, S Donleavy, S Seager, F Gately, A Jolly, L Lahnstein, S Harding, K Daw, M Hedges, R Fraser-Trumble.

We are indebted to the 2,212 women who participated in this randomised trial.

\section{Funding statement}

This project was funded by a four-year project grant from the NHMRC, Australia (ID 519240). JMD is supported through a NHMRC Practitioner Fellowship (ID 627005); LNY is supported through a NHMRC Early Career Fellowship (ID 1052388); and RMG is supported through a NHMRC Early Career Fellowship (ID 1073514). LJM is supported by a South Australian Cardiovascular Research Development Program (SACVRDP) Fellowship (AC11S374); a programme collaboratively funded by the National Heart Foundation of Australia, the South Australian Department of Health and the South Australian Health and Medical Research Institute. Infrastructure support was provided by The University of Adelaide, and the Women's and Children's Hospital, Flinders Medical Centre, and Lyell McEwin Hospital, Adelaide. The funders had no role in the study design, data collection or analysis, decision to publish, or preparation of the manuscript.

\section{Author details}

'School of Paediatrics and Reproductive Health, and The Robinson Research Institute, The University of Adelaide, Adelaide, Australia. ${ }^{2}$ Department of Perinatal Medicine, Women's and Babies Division, The Women's and Children's Hospital, North Adelaide, Australia. 'Women's and Children's Health Research Institute, North Adelaide, Australia. ${ }^{4}$ School of Population Health, The University of Adelaide, Adelaide, Australia. ${ }^{5}$ School of Psychology, The University of Adelaide, Adelaide, AUSTRALIA. ${ }^{6}$ Department of Neonatal Medicine, Women's and Babies Division, The Women's and Children's 
Hospital, North Adelaide, Australia. ' $5 c h o o l$ of Medicine, The University of Adelaide, Adelaide, Australia. ${ }^{8}$ Liggins Institute, The University of Auckland, Auckland, New Zealand.

Received: 24 April 2014 Accepted: 26 August 2014

Published online: 13 October 2014

\section{References}

1. World Health Organisation: Obesity: preventing and managing the global epidemic. WHO Technical Report Series Number 894. Geneva: World Health Organisation; 2000

2. Callaway LK, Prins JB, Chang AM, McIntyre HD: The prevalence and impact of overweight and obesity in an Australian obstetric population. MJA 2006, 184:56-59.

3. Dodd JM, Grivell RM, Nguyen A-M, Chan A, Robinson JS: Maternal and perinatal health outcomes by body mass index category. ANZJOG 2011, 51:136-140

4. NICE Guidelines: Weight management before, during and after pregnancy. [http://www.nice.org.uk/guidance/ph27/resources/guidance-weightmanagement-before-during-and-after-pregnancy-pdf]

5. American College of Obstetricians and Gynecologists: ACOG Committee opinion number 315 , september 2005: obesity in pregnancy. Obstet Gynecol 2005, 106:671-675.

6. Chu SY, Kim SY, Bish CL: Prepregnancy obesity prevalence in the United States, 2004-2005. Maternal Child Health J 2008, Epub.

7. Scheil W, Scott J, Catcheside B, Sage L: Pregnancy outcome in South Australia 2010. In Pregnancy Outcome Unit, SA Health. Adelaide: Government of South Australia; 2012.

8. Dodd JM, Grivell RM, Crowther CA, Robinson JS: Antenatal interventions for overweight or obese pregnant women: a systematic review of randomised trials. Br J Obstet Gynaecol 2010, 117:1316-1326.

9. Oteng-Ntim E, Varma R, Croker H, Poston L, Doyle P: Lifestyle interventions for overweight and obese pregnant women to improve pregnancy outcome: systematic review and meta-analysis. BMC Med 2012, 10:47.

10. Thangaratinam S, Rogozinska E, Jolly K, Glinkowski S, Roseboom T, Tomlinson JW, Kunz R, Mol BW, Coomarasamy A, Khan KS: Effects of interventions in pregnancy on maternal weight and obstetric outcomes: meta-analysis of randomised evidence. BMJ 2012, 344:e2088.

11. Wirt A, Collins CE: Diet quality-what is it and does it matter? Public Health Nutr 2009, 12:2473-2492.

12. Wolongevicz DM, Zhu L, Pencina MJ, Kimokoti RW, Newby PK, D'Agostino $\mathrm{RB}$, Millen BE: Diet quality and obesity in women: the Framingham Nutrition Studies. Br J Nutr 2010, 103:1223-1229.

13. Tsigga M, Filis V, Hatzopoulou K, Kotzamanidis C, Grammatikopoulou MG Healthy Eating Index during pregnancy according to pre-gravid and gravid weight status. Public Health Nutr 2011, 14:290-296.

14. Moran $\mathrm{L}$, Sui Z, Cramp CS, Dodd JM: A decrease in diet quality occurs during pregnancy in overweight and obese women which is maintained post-partum. Int J Obes 2013, 7. May;37(5):704-11. doi:10.1038/ijo.2012.129. Epub 2012 Aug 7.

15. Fazio Ede S, Nomura RM, Dias MC, Zugaib M: Dietary intake of pregnant women and maternal weight gain after nutritional counseling. Rev Bras Ginecol Obstet 2011, 33:87-92.

16. Laraia BA, Bodnar LM, Siega-Riz AM: Pregravid body mass index is negatively associated with diet quality during pregnancy. Public Health Nutr 2007, 10:920-926.

17. Rifas-Shiman SL, Rich-Edwards JW, Kleinman KP, Oken E, Gillman MW: Dietary quality during pregnancy varies by maternal characteristics in Project Viva: a US cohort. J Am Diet Assoc 2009, 109:1004-1011.

18. Jenkins DJ, Wolever TM: Slow release carbohydrate and the treatment of diabetes. Proc Nutr Soc 1981, 40:227-235.

19. Jenkins DJ, Wolever TM, Taylor RH, Barker H, Fielden H, Baldwin JM, Bowling AC, Newman HC, Jenkins AL, Goff DV: Glycemic index of foods: a physiological basis for carbohydrate exchange. Am J Clin Nutr 1981, 34:362-366.

20. Wolever TM, Jenkins DJ: Application of glycaemic index to mixed meals. Lancet 1985, 2:944

21. Thomas DE, Elliott EJ, Baur L: Low glycaemic index or low glycaemic load diets for overweight and obesity. Cochrane Database Syst Rev 2007, 3:CD005105.
22. Walsh JM, MCGowan CA, Mahony R, Foley ME, McAuliffe FM: Low glycaemic index diet in pregnancy to prevent macrosomia (ROLO Study): randomised control trial. BMJ 2012, 345:e5605.

23. Knudsen VK, Heitmann BL, Halldorsson TI, Sørensen TI, Olsen SF: Maternal dietary glycaemic load during pregnancy and gestational weight gain, birth weight and postpartum weight retention: a study within the Danish National Birth Cohort. Br J Nutr 2013, 109:1471-1478.

24. Moses RG, Luebcke M, Davis WS, Coleman KJ, Tapsell LC, Petocz P, Brand-Miller JC: Effect of a low-glycemic-index diet during pregnancy on obstetric outcomes. Am J Clin Nutr 2006, 84:807-812.

25. Grant SM, Wolever TM, O'Connor DL, Nisenbaum R, Josse RG: Effect of a low glycaemic index diet on blood glucose in women with gestational hyperglycaemia. Diabetes Res Clin Pract 2011, 91:15-22.

26. Moses RG, Casey SA, Quinn EG, Cleary JM, Tapsell LC, Milosavljevic M, Petocz P, Brand-Miller JC: Pregnancy and Glycemic Index Outcomes Study: effects of low glycemic index compared with conventional dietary advice on selected pregnancy outcomes. Am J Clin Nutr 2013, [Epub ahead of print]

27. Rhodes ET, Pawlak DB, Takoudes TC, Ebbeling CB, Feldman HA, Lovesky MM, Cooke EA, Leidig MM, Ludwig DS: Effects of a low-glycemic load diet in overweight and obese pregnant women: a pilot randomized controlled trial. Am J Clin Nutr 2010, 92:1306-1315.

28. Clapp JF 3rd: Long-term outcome after exercising throughout pregnancy: fitness and cardiovascular risk. Am J Obstet Gynecol 2008, 199:489. e481-486.

29. Adamu B, Sani MU, Abdu A: Physical exercise and health: a review. Niger J Med 2006, 15:190-196

30. Dempsey JC, Butler CL, Sorensen TK, Lee IM, Thompson ML, Miller RS, Frederick IO, Williams MA: A case-control study of maternal recreational physical activity and risk of gestational diabetes mellitus. Diabetes Res Clin Pract 2004, 66:203-215.

31. Oken E, Ning Y, Rifas-Shiman SL, Radesky JS, Rich-Edwards JW, Gillman MW: Associations of physical activity and inactivity before and during pregnancy with glucose tolerance. Obstet Gynecol 2006, 108:1200-1207.

32. Sorensen TK, Williams MA, Lee IM, Dashow EE, Thompson ML, Luthy DA: Recreational physical activity during pregnancy and risk of preeclampsia. Hypertension 2003, 41:1273-1280.

33. Melzer K, Schutz Y, Boulvain M, Kayser B: Physical activity and pregnancy: cardiovascular adaptations, recommendations and pregnancy outcomes. Sports Med 2010, 40:493-507.

34. Clapp JF: Exercise and pregnancy: a clinical update. Clin Sports Med 2000, 19:273-286

35. Clapp JF, Kim H, Burciu B, Lopez B: Beginning regular exercise in early pregnancy: effect on fetoplacental growth. Am J Obstet Gynecol 2000, 183:1484-1488.

36. American College of Obstetricians and Gynecologists: ACOG Committee Opinion. Exercise during pregnancy and the postpartum period. Number 267, January 2002. American College of Obstetricians and Gynecologists. Int J Gynaecol Obstet 2002, 77:79-81.

37. American College of Obstetricians and Gynecologists: ACOG Committee Opinion no. 549: obesity in pregnancy. Obstet Gynecol 2013, 121:213-217.

38. Davis JN, Hodges VA, Gillham MB: Physical activity compliance: differences between overweight/obese and normal-weight adults. Obesity (Silver Spring) 2006, 14:2259-2265.

39. Gaston A, Cramp A: Exercise during pregnancy: a review of patterns and determinants. J Sci Med Sport 2011, 14:299-305.

40. Poston L, Briley AL, Barr S, Bell R, Croker H, Coxon K, Essex HN, Hunt C, Hayes L, Howard LM, Khazaezadeh N, Kinnunen T, Nelson SM, Oteng-Ntim E, Robson SC, Sattar N, Seed PT, Wardle J, Sanders TA, Sandall J: Developing a complex intervention for diet and activity behaviour change in obese pregnant women (the UPBEAT trial); assessment of behavioural change and process evaluation in a pilot randomised controlled trial. BMC Pregnancy Childbirth 2013, 13:148

41. Dodd JM, Turnbull DA, McPhee AJ, Deussen AR, Grivell RM, Yelland LN, Crowther CA, Wittert G, Owens JA, Robinson JS: Antenatal lifestyle advice for women who are overweight or obese: the LIMIT randomised trial. BMJ 2014, 348:91285.

42. Dodd JM, Turnbull DA, McPhee AJ, Wittert G, Crowther CA, Robinson JS: Limiting weight gain in overweight and obese women during pregnancy to improve health outcomes: the LIMIT randomised controlled trial. BMC Pregnancy Childbirth 2011, 11:79.

43. Australian Guide to Healthy Eating. [http://www.eatforhealth.gov.au/ guidelines/australian-guide-healthy-eating] 
44. Royal College of Obstetricians and Gynaecologists RCOG: Recreational Exercise and Pregnancy: Information for You. RCOG Press; 2006.

45. Artal R, O'Toole M: Guidelines of the American College of Obstetricians and Gynecologists for exercise during pregnancy and the postpartum period. Br J Sports Med 2003, 37:6-12. discussion 12.

46. Willett WC, Reynolds RD, Cottrell-Hoehner S, Sampson L, Browne ML: Validation of a semi-quantitative food frequency questionnaire: comparison with a 1-year diet record. J Am Diet Assoc 1987, 87:43-47.

47. Fawzi WW, Rifas-Shiman SL, Rich-Edwards JW, Willett WC, Gillman MW: Calibration of a semi-quantitative food frequency questionnaire in early pregnancy. Ann Epidemiol 2004, 14:754-762.

48. Rumbold AR, Crowther CA, Haslam RR, Dekker GA, Robinson JS, Group. ftAS: Vitamins $C$ and $E$ and the risks of preeclampsia and perinatal complications. N Engl J Med 2006, 354:1796-1806.

49. NUTTAB: Australian food composition tables: Food Standards Australia New Zealand, Canberra. 2010, [http://www.foodstandards.gov.au/science/ monitoringnutrients/nutrientables/pages/default.aspx]

50. Guenther PM, Reedy J, Krebs-Smith SM: Development of the Healthy Eating Index-2005. J Am Diet Assoc 2008, 108:1896-1901.

51. Pick ME, Edwards M, Moreau D, Ryan EA: Assessment of diet quality in pregnant women using the Healthy Eating Index. J Am Diet Assoc 2005, 105:240-246.

52. Wendel-Vos GC, Schuit AJ, Saris WH, Kromhout D: Reproducibility and relative validity of the short questionnaire to assess health-enhancing physical activity. J Clin Epidemiol 2003, 56:1163-1169.

53. Scholten RR, Oyen WJ, Van der Vlugt MJ, Van Dijk AP, Hopman MT, Lotgering FK, Spaanderman ME: Impaired fetal growth and low plasma volume in adult life. Obstet Gynecol 2011, 18:1314-1322.

54. Althuizen E, van Poppel MNM, de Vries JH, Seidell JC, van Mechelen W: Postpartum behaviour as predictor of weight change from before pregnancy to one year postpartum. BMC Public Health 2011, 11:165.

55. Ainsworth BE, Haskell WL, Herrmann SD, Meckes N, Bassett DRJ, Tudor-Locke C, Greer JL, Vezina J, Whitt-Glover MC, Leon AS: Compendium of physical activities: a second update of codes and MET values. Med Sci Sports Exerc 2011, 2011:1575-1581.

56. Meltzer HM, Brantsaeter AL, Ydersbond TA, Alexander J, Haugen M: Methodological challenges when monitoring the diet of pregnant women in a large study: experiences from the Norwegian Mother and Child Cohort Study. Matern Child Nutr 2008, 4:14-27.

57. Socio-Economic Indexes for Areas. [http://www.abs.gov.au/websitedbs/ censushome.nsf/home/seifa2011?opendocument\&navpos=260]

58. Mangou A, Grammatikopoulou MG, Mirkopoulou D, Sailer N, Kotzamanidis C, Tsigga M: Associations between diet quality, health status and diabetic complications in patients with type 2 diabetes and comorbid obesity. Endocrinol Nutr 2012, 59:109-116.

59. Nicklas TA, O'Neil CE, Fulgoni VL: Diet quality is inversely related to cardiovascular risk factors in adults. J Nutr 2012, 142:2112-2118.

60. Shah BS, Freeland-Graves JH, Cahill JM, Lu H, Graves GR: Diet quality as measured by the healthy eating index and the association with lipid profile in low-income women in early postpartum. J Am Diet AssoC 2010, 110:274-279.

61. Guelinckx I, Devlieger R, Mullie P, Vansant G: Effect of a lifestyle intervention on dietary habits, physical activity, and gestational weight gain in obese pregnant women: a randomized controlled trial. Am J Clin Nutr 2010, 91:373-380.

62. Rae A, Bond D, Evans SF, North F, Roberman B, Walters B: A randomised controlled trial of dietary energy restriction in the management of obese women with gestational diabetes. ANZJOG 2000, 40:416-422.

63. Wolff S, Legarth J, Vangsgaard K, Toubro S, Astrup A: A randomized trial of the effects of dietary counseling on gestational weight gain and glucose metabolism in obese pregnant women. Int J Obes 2008, 32:495-501.

64. Pedersen J: Weight and length at birth of infants of diabetic mothers. Acta Endocrinol (Copenh) 1954, 16:330-342.

65. Catalano PM, Hauguel-De Mouzon S: Is it time to revisit the Pedersen hypothesis in the face of the obesity epidemic? Am J Obstet Gynecol 2011, 204:479-487.

66. Doumouchtsis SK, Arulkumaran S: Are all brachial plexus injuries caused by shoulder dystocia? Obstet Gynecol Surv 2009, 64:615-623.

67. Okereke NC, Huston-Presley L, Amini SB, Kalhan S, Catalano PM: Longitudinal changes in energy expenditure and body composition in obese women with normal and impaired glucose tolerance. Am J Physiol Endocrinol Metab 2004, 287:E472-E479.
68. Butte NF, King JC: Energy requirements during pregnancy and lactation. Public Health Nutr 2005, 8:1010-1027.

69. Ley SH, Hanley AJ, Retnakaran R, Sermer M, Zinman B, O'Connor DL: Effect of macronutrient intake during the second trimester on glucose metabolism later in pregnancy. Am J Clin Nutr 2011, 94:1232-1240.

70. Donahue SM, Rifas-Shiman SL, Gold DR, Jouni ZE, Gillman MW, Oken E: Prenatal fatty acid status and child adiposity at age $3 \mathrm{y}$ : results from a US pregnancy cohort. Am J Clin Nutr 2011, 93:780-788.

71. Moon RJ, Harvey NC, Robinson SM, Ntani G, Davies JH, Inskip HM, Godfrey KM, Dennison EM, Calder PC, Cooper C, SWS Study Group: Maternal plasma polyunsaturated fatty acid status in late pregnancy is associated with offspring body composition in childhood. J Clin Endocrinol Metab 2013, 98:299-307.

72. Evenson KR, Chasan-Taber L, Symons Downs D, Pearce EE: Review of self-reported physical activity assessments for pregnancy: summary of the evidence for validity and reliability. Paediatr Perinat Epidemiol 2012, 26:479-494.

73. Chasan-Taber L, Evenson KR, Sternfeld B, Kengeri S: Assessment of recreational physical activity during pregnancy in epidemiologic studies of birthweight and length of gestation: methodologic aspects. Women Health 2007, 45:85-107.

74. Kinnunen TI, Tennant PW, McParlin C, Poston L, Robson SC, Bell R: Agreement between pedometer and accelerometer in measuring physical activity in overweight and obese pregnant women. BMC Public Health 2011, 11:501. doi:10.1186/1471-2458-11-501

75. Schmidt MD, Pekow P, Freedson PS, Markenson G, Chasan-Taber L: Physical activity patterns during pregnancy in a diverse population of women. J Women's Health 2006, 15:909-918.

76. Chandonnet N, Saey D, Alméras N, Marc I: French Pregnancy Physical Activity Questionnaire compared with an accelerometer cut point to classify physical activity among pregnant obese women. PLoS One 2012, 7:e38818.

77. McParlin C, Robson SC, Tennant PW, Besson H, Rankin J, Adamson AJ, Pearce MS, Bell R: Objectively measured physical activity during pregnancy: a study in obese and overweight women. BMC Pregnancy Childbirth 2010, 10:76. doi:10.1186/1471-2393-10-76.

doi:10.1186/s12916-014-0161-y

Cite this article as: Dodd et al.: The effects of antenatal dietary and lifestyle advice for women who are overweight or obese on maternal diet and physical activity: the LIMIT randomised trial. BMC Medicine 2014 12:161

\section{Submit your next manuscript to BioMed Central and take full advantage of:}

- Convenient online submission

- Thorough peer review

- No space constraints or color figure charges

- Immediate publication on acceptance

- Inclusion in PubMed, CAS, Scopus and Google Scholar

- Research which is freely available for redistribution

Submit your manuscript at www.biomedcentral.com/submit
C) Biomed Central 